\title{
Incorporação de ar em argamassas estabilizadas: influência dos aditivos, agregados e tempo de mistura
}

\author{
Air incorporation in ready mix mortars: influence of \\ admixtures, aggregates and mixing time
}

\section{Juliana Pippi Antoniazzi \\ Gihad Mohamad \\ Juliana Machado Casali \\ Raquel Petry Brondani Schmidt}

\section{Resumo}

A

incorporação de ar em argamassas é um tema complexo que afeta suas propriedades no estado fresco e endurecido. A argamassa estabilizada é uma mistura pronta que contém alto teor de ar incorporado e possui aplicabilidade de até três dias devido ao emprego dos aditivos incorporadores de ar (AIA) e estabilizadores de hidratação (AEH). Este trabalho avaliou a influência dos aditivos AIA e AEH do tipo de agregado e o tempo de mistura na incorporação de ar de argamassas. Para tanto, foram confeccionadas 36 misturas de argamassas, submetidas a diferentes tempos de mistura (150s, 210s, 270s e 330s). Foram estudadas duas granulometrias de areias, empregando-se os teores do AEH $(0 \%, 0,6 \%$ e $0,9 \%)$ e do AIA $(0 \%$ a $0,5 \%)$, traço padrão para revestimentos (1:6,5) e proporção água/aglomerante de 1,0 . Os resultados apontaram para uma estabilização da incorporação de ar com tempo de mistura de 270 s e teor do AIA entre $0,3 \%$ e $0,4 \%$, enquanto o AEH não contribuiu significativamente para a incorporação de ar. $\mathrm{O}$ tempo de mistura influenciou a incorporação de ar das argamassas apenas para teores de AIA a partir de $0,3 \%$, já a granulometria do agregado influenciou apenas nas argamassas sem AIA ou com AIA até $0,2 \%$.

Palavras-chave: Argamassa estabilizada. Incorporação de ar. Aditivo incorporador de ar. Aditivo estabilizador de hidratação. Tempo de mistura.

1Juliana Pippi Antoniazzi 'Universidade Federal de Santa Maria Santa Maria - RS - Brasil

${ }^{2}$ Gihad Mohamad ${ }^{2}$ Universidade Federal de Santa Maria Santa Maria - RS - Brasil

${ }^{3} J u l i a n a$ Machado Casali ${ }^{3}$ Instituto Federal de Santa Catarina Florianópolis - SC - Brasil

${ }^{4}$ Raquel Petry Brondani Schmidt ${ }^{4}$ Universidade Federal de Santa Maria Santa Maria - RS - Brasil

Recebido em 16/09/19 Aceito em 14/04/20

\begin{abstract}
Airincorporation is a complex issue that affects the properties of both fresh and hardened mortars. Ready-mix mortar is a mix that contains a high content of entrainedair, and has an applicability of up to three days due to the use of air entraining admixtures (AEA) and hydration stabilising admixtures (HSA). This study evaluated the influence of AEA and HSA, aggregate type and mixing time on air entrainment in ready-mix mortars. In the investigation, 36 mortar mixtures were prepared with different mixing times (150, 210, 270 and 330 s). Two sand particle sizes were studied, using different contents of $H S A(0 \%, 0.6 \%$ and $0.9 \%)$ and AEA (0\% to 0.5\%), a standard proportion for rendering mortars (1:6.5) and a water/binder ratio of 1.0. The results indicated air entrainment stabilisation with a mixing time of 270 seconds and an AIA content between $0.3 \%$ and $0.4 \%$, whereas HSA did not contribute significantly to air entrainment. Mixing time influenced air entrained in mortars only with an AEA content $0.3 \%$ or higher, while aggregate particle size only influenced mortars without AEA or with AEA up to $0.2 \%$.
\end{abstract}

Keywords: Ready mix mortar. Air incorporation. Air entrained admixture. Hydration stabilising admixture. Mixing time. 


\section{Introdução}

A incorporação de ar em argamassas proporciona maior trabalhabilidade e coesão às misturas, diminuindo a tendência à exsudação (BENINGFIELD, 1988; ALVES, 2002) e aumentando a produtividade em obra. Essa incorporação intencional de ar geralmente é feita com a utilização de aditivo incorporador de ar (AIA), o qual proporciona, juntamente com o processo mecânico de mistura, a introdução de microbolhas de ar estáveis na argamassa. O atrito interno entre as partículas é então diminuído, promovendo maior distanciamento entre os agregados, o que facilita o fluxo, manuseio e aplicação (ROMANO; CINCOTTO; PILEGGI, 2018). Dessa forma, a consistência das misturas com ar incorporado tende a ser menor do que a de misturas convencionais, uma vez que, diferentemente das pastas de cimento onde o efeito ponte é predominante, com a presença do agregado o efeito que predomina é das bolhas de ar funcionando como microesferas compressíveis, melhorando o rolamento entre os grãos.

Segundo Beningfield (1988), se as argamassas receberem teores de ar incorporado entre $20 \%$ e $25 \%$, tornase perceptível uma redução em suas resistências. Entre percentuais de $15 \%$ e $20 \%$, para a maioria do tipo de ar incorporado pode haver uma pequena redução das propriedades no estado endurecido, sendo assim recomenda-se um máximo de $20 \%$ para o teor de ar incorporado.

A incorporação de ar e a modificação das propriedades da argamassa pelo uso do AIA irão depender de vários fatores, dentre estes o tempo e a energia de mistura, o tipo de misturador, o teor de aditivos empregado e a granulometria do agregado (ALVES, 2002; ROMANO et al., 2009; ROMANO; TORRES; PILEGGI, 2015; ROMANO; CINCOTTO; PILEGGI, 2018).

Hoje em dia o mercado da construção civil tem utilizado muito as argamassas estabilizadas como opção de revestimento, as quais são produzidas e dosadas em central, com capacidade de manterem-se trabalháveis por até três dias. Para isso, os fabricantes trabalham com altos índices de teor de ar incorporado aliados ao efeito de retardo do tempo de pega (NELSON et al., 1988). Nesse caso, o aditivo incorporador de ar (AIA) é o responsável pela melhora nessa trabalhabilidade da argamassa no estado fresco, enquanto o aditivo estabilizador de hidratação $(\mathrm{AEH})$ possibilita um aumento no tempo em que essa mistura permanece trabalhável.

Os aditivos incorporadores de ar são agentes tensoativos, na grande maioria aniônicos, formados por moléculas de cabeça hidrofílica e cauda hidrofóbica que, quando posicionados na interface ar-água, reduzem a tensão superficial e promovem a incorporação de ar (HARTMANN et al., 2011; ROMANO; CINCOTTO; PILEGGI, 2018). Na interface sólido-água, os tensoativos posicionam-se de forma que o grupo polar, carregado negativamente, fique em contato com as partículas de cimento e/ou agregados, carregadas positivamente em sua superfície, ficando o grupo apolar em contato com a água (SALAGER, 2002; MEHTA; MONTEIRO, 2014).

Os aditivos estabilizadores de hidratação são um tipo de retardador de pega, os quais se diferenciam deste por promoverem retardo da ação química entre o cimento e a água de longa extensão (MEHTA; MONTEIRO, 2014), uma vez que atuam sobre todos os minerais do clínquer. Esses aditivos atuam como agentes ativos de superfície, formando uma película hidrorrepelente ao redor das partículas de cimento e inibindo a nucleação na superfície de hidratos ricos em íons de cálcio. Dessa forma, quando acrescentados juntos à água de amassamento, inibem a nucleação e a formação do silicato de cálcio hidratado (PAOLINI; KHURANA, 1998; RICKERT; THILEN, 2004).

As argamassas estabilizadas não possuem normativas específicas para nortear sua produção e aplicação, ao mesmo tempo que suas propriedades possuem características bastante específicas devido ao emprego de diferentes aditivos, conforme a indústria produtora de argamassa.

A motivação para este estudo diz respeito ao interesse da indústria em resolver problemas identificados na produção de argamassas estabilizadas, devido à variabilidade dos resultados físicos e mecânicos produzidos pelo uso dos aditivos. Existem ainda questionamentos sob a interação entre os aditivos estabilizadores de hidratação (AEH) e os incorporadores de ar (AIA) nessas argamassas, o quanto o teor de cada aditivo empregado influencia no teor de ar das argamassas, observando se ocorre um ponto de saturação dessas moléculas, assim como até que ponto a incorporação de ar está atrelada ao tempo de mistura e se a granulometria da areia também exerce influência nesse processo.

Este trabalho, portanto, tem por objetivo avaliar a interação entre os aditivos incorporadores de ar e estabilizadores de hidratação na incorporação de ar das argamassas. Para tanto foram quantificados o teor de incorporação de ar das amostras quando submetidas a diferentes tempos de mistura e teores dos aditivos AIA e AEH, para duas diferentes faixas granulométricas de areia. 


\section{Fatores que interferem na incorporação de ar de argamassas}

Estudos realizados por Ferraris, Obla e Hill (2001), Alves (2002), Romano et al. (2009) em argamassas de revestimento mostraram uma correlação linear e diretamente proporcional entre o tempo de mistura e o teor de ar incorporado. Segundo Ramachandran (1984), Beningfield (1988), Rixon e Mailvaganan (1999), em misturas com baixo teor de materiais sólidos o nível máximo de ar incorporado é rapidamente alcançado, sendo progressivamente menor com o aumento do tempo de mistura. Já para misturas com alto teor de sólidos são requeridos entre 5 e 10 minutos para se atingir o teor máximo de ar, tendendo a diminuir os valores com a continuação da mistura.

Com o aumento do tempo de mistura e dos movimentos diferenciais produzidos pelo cisalhamento entre partículas as bolhas de ar incorporadas à massa se subdividem em bolhas menores, as quais são mais instáveis termodinamicamente, pois a pressão interna torna-se maior. Dessa forma, a tendência é que a velocidade de incorporação diminua a partir de certo ponto, já que o volume de pasta disponível também se torna menor. Esse processo ocorre até que seja atingido um volume limite de ar, a partir do qual se observa a diminuição da incorporação de ar devido à tendência das bolhas coalescerem (ROMANO, 2013).

Naturalmente, como observado por Bauer e Oliveira (2017), o aumento do teor de aditivo incorporador de ar (AIA) proporciona um incremento na porosidade das misturas de argamassa. Porém, na teoria esse aumento ocorre de forma significativa até um limite de saturação das moléculas de aditivo, denominado concentração micelar crítica (SALEGER, 1993; ROMANO, 2013), como mostra a Figura 1.

Segundo Salager (1993), a partir da concentração micelar crítica (CMC) ocorre a saturação de moléculas de incorporador de ar, podendo ser observada pela Figura 1 uma transição da fase (ii) para a fase (iii), onde a tensão superficial não mais se altera mesmo com o aumento da concentração de aditivo. Nessa fase qualquer molécula suplementar de aditivo incorporador de ar ficará acima desse limite de saturação e a solubilização irá gerar micelas, isto é, agregados do tipo coloidais, não havendo mais efeito na incorporação de ar.

Quando estudadas apenas pastas de cimento, Antoniazzi et al. (2019) observaram que o aditivo estabilizador de hidratação (AEH) também possui capacidade de incorporação de ar. Porém, Bauer e Oliveira (2017) afirmam que quando adicionado areia, formando a argamassa, o AEH só contribuiu com a incorporação de ar quando empregado em conjunto com o AIA.

$\mathrm{Na}$ pesquisa de Araujo (2005) foi constatado que o aumento do teor de aditivo não alterou de maneira significativa a quantidade de ar incorporado.

Figura 1 - Concentração micelar crítica (CMC) dos aditivos incorporadores de ar

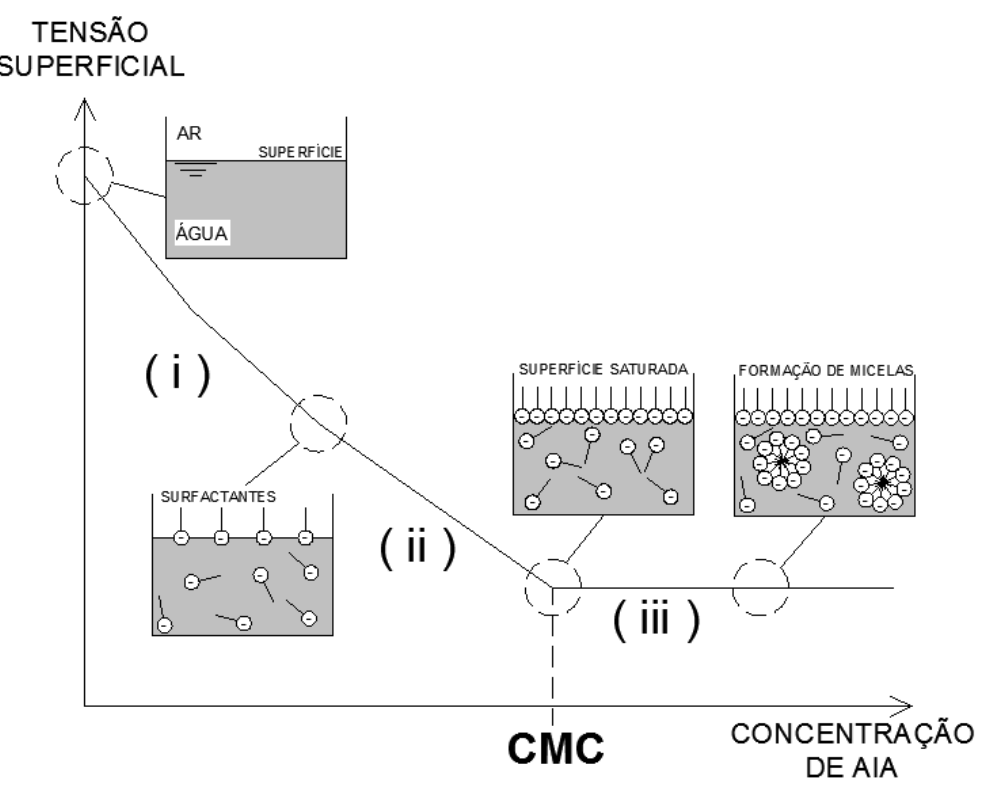

Fonte: adaptado de Romano (2013). 
Segundo Romano (2013), a granulometria do agregado miúdo também pode interferir no processo de incorporação de ar, uma vez que, quanto maior a quantidade de partículas finas, mais água é necessário para atingir uma mesma consistência na mistura. Assim, teoricamente para uma relação água/aglomerante constante, o emprego de uma granulometria mais fina resultaria em menor quantidade de água livre disponível para a incorporação de ar, proporcionando menor teor de ar incorporado.

Segundo Silva (2014) e Haddad et al. (2016), agregados com distribuição contínua tendem a incorporar menos ar, enquanto granulometrias uniformes são mais propícias à incorporação de ar.

O trabalho de Romano, Torres e Pileggi (2015) mostrou que as variações na distribuição granulométrica dos agregados causam impacto considerável durante a fase de mistura, os quais são diminuídos pela utilização de aditivos incorporadores de ar.

A introdução proposital de ar às misturas também pode ser empregada visando suprir as lacunas deixadas por distribuições granulométricas descontínuas, amenizando as disparidades nas propriedades ocasionadas por esse fator, já que o emprego do AIA às argamassas introduz microbolhas de ar estáveis que preenchem os espaços e facilitam o fluxo.

\section{Materiais e métodos}

Este estudo avaliou misturas de argamassas confeccionadas em laboratório, utilizando dois diferentes tipos de agregados miúdos, juntamente com os aditivos AEH e AIA em teores variados, aplicando-se, ainda, diferentes tempos de mistura.

Os materiais utilizados para o desenvolvimento do programa experimental foram obtidos nas empresas produtoras de argamassas estabilizadas da Região Sul para revestimento.

O cimento utilizado nessa pesquisa foi o CP II F - 40, da Votorantim. Os ensaios de caracterização do cimento encontram-se nas Tabelas 1 e 2.

Tabela 1 - Características físicas do cimento CPII F-40

\begin{tabular}{c|c|c}
\hline Propriedade & CPII-40 & Método \\
\hline Massa específica $\left(\mathrm{g} / \mathrm{cm}^{3}\right)$ & 3,1 & NBR 16605 (ABNT, 2017) \\
Índice de finura (\#0,075mm) $(\%)$ & 0,12 & NBR 11579 (ABNT, 2013) \\
Água da pasta de consistência normal (\%) & 29 & NBR 16606 (ABNT, 2018a) \\
Início de pega (h:min) & $4: 00$ & NBR 16607 (ABNT, 2018b) \\
Fim de pega (h:min) & $5: 20$ & NBR 16607 (ABNT, 2018b) \\
Área superficial $\left(\mathrm{m}^{2} / \mathrm{g}\right)$ & 1,2592 & BET \\
Volume dos poros $\left(\mathrm{cm}^{3} / \mathrm{g}\right)$ & 0,004791 & BET \\
Dimensão dos poros $(\mathrm{nm})$ & 20,0047 & BJH/BET \\
\hline
\end{tabular}

Tabela 2 - Características químicas, físicas e mecânicas do cimento CPII F-40

\begin{tabular}{|c|c|c|c|c|}
\hline & & Cimento F & Limite de norma & Normativa \\
\hline \multicolumn{5}{|c|}{ Ensaios químicos } \\
\hline \multicolumn{2}{|c|}{ Perda ao fogo (\%) } & 4,86 & $\leq 6,5$ & NBR NM 18 (ABNT, 2012a) \\
\hline \multicolumn{2}{|c|}{ Óxido de magnésio (\%) } & 5,90 & $\leq 6,5$ & NBR NM 14 (ABNT, 2012b) \\
\hline \multicolumn{2}{|c|}{ Anidrido sulfúrico (\%) } & 3,56 & $\leq 4,0$ & NBR NM 16 (ABNT, 2012c) \\
\hline \multicolumn{2}{|c|}{ Resíduo insolúvel (\%) } & 0,82 & $\leq 2,5$ & NBR NM 22 (ABNT, 2012d) \\
\hline \multicolumn{5}{|c|}{ Ensaios físicos e mecânicos } \\
\hline \multicolumn{2}{|c|}{ Blaine $\left(\mathrm{cm}^{2} / \mathrm{g}\right)$} & 4521,50 & $\geq 2800$ & NBR 16372 (ABNT, 2015) \\
\hline \multicolumn{2}{|c|}{ Expansibilidade a quente (mm) } & 0,38 & $\leq 5,0$ & NBR 11582 (ABNT, 2016) \\
\hline \multirow{4}{*}{$\begin{array}{l}\text { Resistência à } \\
\text { compressão }\end{array}$} & 1 dia & 23,73 & N/A & \multirow{4}{*}{ NBR 7215 (ABNT, 2019) } \\
\hline & 3 dias & 34,47 & $\geq 15,0$ & \\
\hline & 7 dias & 40,25 & $\geq 25,0$ & \\
\hline & 28 dias & 47,68 & $\geq 40,0$ & \\
\hline
\end{tabular}

Fonte: fabricante de cimentos, unidade Rio Branco (DEZ/2017). 
Foram empregados dois tipos de agregados miúdos nesta pesquisa, aqui denominados de areia A e areia B. A areia A foi extraída de rio, na cidade de Santa Maria, RS, enquanto a Areia B era proveniente de cava, da localidade de Viamão, RS. As características de ambos os agregados estão especificadas na Tabela 3.

As granulometrias dos agregados empregados foram realizadas conforme a NBR NM 248 (ABNT, 2003a) e pode ser verificada na Figura 2, para as areias tipo A e B. Anteriormente aos ensaios, os agregados foram secos em estufa por $24 \mathrm{~h}$.

Para a confecção das misturas das argamassas foram utilizados dois tipos de aditivos, um aditivo incorporador de ar (AIA) de caráter aniônico e um aditivo estabilizador de hidratação (AEH), adicionados juntamente com a água, na fase inicial da mistura. Os dados técnicos dos aditivos encontram-se na Tabela 4.

Todas as misturas foram confeccionadas com o mesmo traço de 1:6,5, em massa, e a mesma proporção água/aglomerante de 1,0. Dessa forma, foram propostas 36 misturas de argamassas, sendo 18 com um tipo de agregado miúdo - areia $\mathrm{A}$ - e $18 \mathrm{com}$ a segunda granulometria - areia $\mathrm{B}$. Cada mistura (M) foi designada com uma numeração específica, com o tipo de agregado (areia A ou B), e foram subscritos os teores AEH e AIA, respectivamente, conforme Figura 3.

Tabela 3 - Propriedades dos agregados miúdos

\begin{tabular}{c|c|c|c}
\hline Propriedade & Areia A & Areia B & Método \\
\hline Dimensão máxima característica $(\mathrm{mm})$ & 1,20 & 0,60 & NBR NM 248(ABNT, 2003a) \\
Módulo de finura & 1,73 & 1,48 & NBR NM 248 (ABNT, 2003a) \\
Massa específica $\left(\mathrm{g} / \mathrm{cm}^{3}\right)$ & 2,64 & 2,67 & NBR NM 52 (ABNT, 2009) \\
Massa unitária $\left(\mathrm{g} / \mathrm{cm}^{3}\right)$ & 1,63 & 1,63 & NBR NM 45 (ABNT, 2006) \\
Teor de material pulverulento $(\%)$ & 4,94 & 2,13 & NBR NM 46 (ABNT, 2003b) \\
Área superficial $\left(\mathrm{m}^{2} / \mathrm{g}\right)$ & 0,54 & 1,31 & BET \\
Volume dos poros $\left(\mathrm{cm}^{3} / \mathrm{g}\right)$ & 0,001156 & 0,003719 & BET \\
Dimensão dos poros $(\mathrm{nm})$ & 8,48 & 10,24 & BJH/BET \\
\hline
\end{tabular}

Figura 2 - Granulometria das areias A e B

\begin{tabular}{c|c|c|c|c}
\hline \multirow{2}{*}{$\begin{array}{c}\text { Peneira } \\
(\mathbf{m m})\end{array}$} & \multicolumn{2}{|c|}{ Areia A } & \multicolumn{2}{c}{ Areia B } \\
\cline { 2 - 5 } & \multicolumn{2}{|c|}{ Médias } & \multicolumn{2}{c}{ Médias } \\
\cline { 2 - 5 } & $\begin{array}{c}\% \\
\text { Retida }\end{array}$ & $\begin{array}{c}\text { \% Retida } \\
\text { acumulada }\end{array}$ & $\begin{array}{c}\text { \% } \\
\text { Retida }\end{array}$ & $\begin{array}{c}\text { \% Retida } \\
\text { acumulada }\end{array}$ \\
\hline 9,50 & $0,00 \%$ & $0,00 \%$ & $0,00 \%$ & $0,00 \%$ \\
4,80 & $0,08 \%$ & $0,08 \%$ & $0,00 \%$ & $0,00 \%$ \\
2,40 & $0,40 \%$ & $0,47 \%$ & $0,00 \%$ & $0,00 \%$ \\
1,20 & $1,78 \%$ & $2,25 \%$ & $0,06 \%$ & $0,06 \%$ \\
0,60 & $15,19 \%$ & $17,45 \%$ & $4,05 \%$ & $4,11 \%$ \\
0,30 & $51,31 \%$ & $68,76 \%$ & $42,87 \%$ & $46,99 \%$ \\
0,15 & $15,33 \%$ & $84,08 \%$ & $49,91 \%$ & $96,90 \%$ \\
fundo & $15,92 \%$ & $100,00 \%$ & $3,10 \%$ & $100,00 \%$ \\
\hline
\end{tabular}

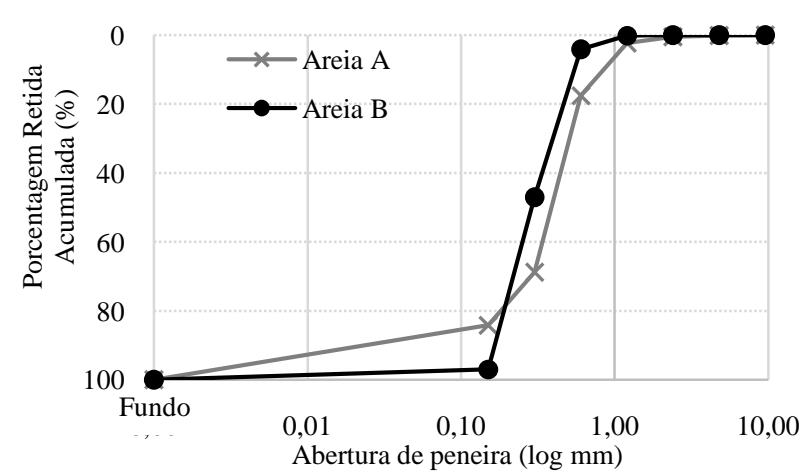

Tabela 4 - Dados técnicos dos aditivos incorporador de ar (AIA) e estabilizador de hidratação (AEH)

\begin{tabular}{c|c|c}
\hline Características & AIA & AEH \\
\hline Base química & Sal de álcool graxo etoxilado sulfatado & - \\
Aspecto & Líquido & Líquido \\
Cor & Amarelo & Marrom \\
Densidade $(\mathrm{g} / \mathrm{cm} 3)$ & 1,00 & 1,17 \\
Teor de sólidos $(\%)$ & 3 & 45 \\
$\mathrm{pH}$ & 9 & 6 \\
Solubilidade & Solúvel em água $\left(20{ }^{\circ} \mathrm{C}\right)$ & Solúvel em água \\
Dosagens $(\%$ peso do cimento $)$ & $0,1-0,5$ & $0,2-1,5$ \\
\hline
\end{tabular}

Fonte: fabricante de aditivo. 
Figura 3 - Nomenclaturas das misturas

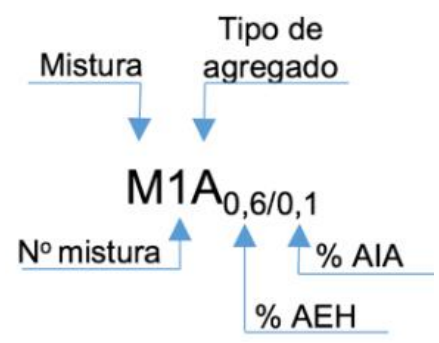

Todos os teores utilizados para os aditivos são em relação à massa do cimento e foram estipulados dentro dos limites sugeridos por seus fabricantes, os quais indicam dosagens para o AEH entre $0,2 \%$ e $1,5 \%$ e para o AIA entre $0,1 \%$ e $0,5 \%$. Dessa forma, para as misturas desta pesquisa escolheram-se dois teores do AEH de $0,6 \%$ e $0,9 \%$, conforme utilizado por fabricantes regionais de argamassas para os traços de argamassa estabilizada de $36 \mathrm{~h}$ e $72 \mathrm{~h}$. Já para o AIA, o qual interfere diretamente no teor de ar incorporado, optou-se por trabalhar com cinco teores distintos de aditivo, sendo estes $0,1 \%, 0,2 \%, 0,3 \%, 0,4 \%$ e $0,5 \%$, buscando-se melhor entender os efeitos proporcionados às misturas. A Tabela 5 apresenta as misturas de argamassas e suas devidas nomenclaturas.

As misturas das argamassas foram realizadas em uma argamassadeira de eixo vertical com capacidade de 5 litros e com movimento planetário. O procedimento de mistura foi realizado com base no descrito na NBR 7215 (ABNT, 2019), com adaptações para a inclusão de aditivos e no tempo de repouso.

Assim, a mistura das argamassas deu-se na seguinte sequência, denominada aqui de procedimento padrão de mistura (PP): inicialmente colocou-se toda a água (nas misturas com aditivos, que foram adicionados nesse momento e misturados em velocidade baixa com a água durante 20s para homogeneização) e posteriormente todo o cimento. Misturou-se então durante 30s (velocidade baixa) e, sem paralisar o equipamento, iniciou-se a colocação da areia, dentro de um período de 30s. Mudou-se a velocidade para alta e os materiais foram misturados por mais 30s, sendo o misturador desligado (15s) para a retirada da argamassa aderida às paredes e à pá. $\mathrm{O}$ misturador era novamente ligado em velocidade alta por mais $60 \mathrm{~s}$, totalizando um tempo total de mistura de 150s.

Após a mistura do procedimento padrão, foi determinado o teor de ar incorporado das argamassas, conforme a NBR 13278 (2005), as quais foram, posteriormente, submetidas novamente ao processo de mistura na argamassadeira, com incrementos de tempo de 60s. Assim, as argamassas eram ensaiadas novamente para o teor de ar incorporado, repetindo-se o processo após cada incremento de tempo. Os tempos de mistura estudados foram 150s (PP), 210s, 270s e 330s. O volume das misturas permaneceu sempre constante, a fim de não influenciar na incorporação de ar. As determinações do teor de ar incorporado das amostras foram feitas a partir da média de três medições para cada tempo de mistura e proporção entre os aditivos (AEH e AIA).

Dessa forma, buscou-se encontrar o tempo de mistura no qual a incorporação de ar seja estabilizada, assim como os teores de aditivos a partir dos quais não ocorra mais um aumento significativo do teor de ar incorporado. Para fins de verificação, foi confeccionada uma segunda mistura de cada argamassa, aplicandose o tempo total de mistura obtido com as análises, agora de forma ininterrupta, observando-se o teor de ar incorporado médio obtido apresentava divergência do obtido com os incrementos de tempo, avaliando assim a influência das pausas no processo de incorporação.

A microscopia eletrônica de varredura (MEV) foi utilizada para análise qualitativa dos poros gerados. $\mathrm{O}$ equipamento utilizado para os ensaios foi o VEGA3, da marca Tescan, utilizando- se o detector do tipo elétrons secundários ("secondaryelectron" - SE), resultantes de baixa energia $(<50 \mathrm{eV})$ que formam imagens com alta resolução $(3-5 \mathrm{~nm})$. As amostras foram retiradas da parte central do corpo de prova prismático $(4 \times 4 \times 16 \mathrm{~cm})$ de argamassas curadas em ambiente de laboratório, após o ensaio de compressão (28d), excluindo-se as extremidades. As amostras foram submetidas ao forno com temperatura de $40{ }^{\circ} \mathrm{C}$ durante 24 horas.

Os resultados deste trabalho foram analisados utilizando-se o programa SPSS (Statistical Package for Social Sciences, versão 20.0), sendo os dados comparados entre as diferentes misturas e propriedades por meio dos Testes T e ANOVA com post hoc de Tukey $(\mathrm{p}<0,05)$. 
Tabela 5 - Fluxograma do programa experimental

\begin{tabular}{|c|c|c|c|}
\hline \multirow{2}{*}{ AEH } & \multirow{2}{*}{ AIA } & \multicolumn{2}{|c|}{ Nomenclatura } \\
\hline & & Areia A & Areia B \\
\hline 0,00 & 0,00 & $\mathrm{M} 1 \mathrm{~A}_{0,0 / 0,0}$ & $\mathrm{M}_{1 \mathrm{~B}} \mathrm{~B}_{0,0 / 0,0}$ \\
\hline 0,60 & 0,00 & $\mathrm{M} 2 \mathrm{~A}_{0,6 / 0,0}$ & $\mathrm{M} 2 \mathrm{~B}_{0,6 / 0,0}$ \\
\hline 0,90 & 0,00 & $\mathrm{M}_{3} \mathrm{~A}_{0,9 / 0,0}$ & $\mathrm{M}_{3} \mathrm{~B}_{0,9 / 0,0}$ \\
\hline 0,00 & 0,10 & $\mathrm{M}_{4} \mathrm{~A}_{0,0 / 0,1}$ & $\mathrm{M}_{4} \mathrm{~B}_{0,0 / 0,1}$ \\
\hline 0,00 & 0,20 & $\mathrm{M} \mathrm{A}_{0,0 / 0,2}$ & $\mathrm{M} \mathrm{B}_{0,0 / 0,2}$ \\
\hline 0,00 & 0,30 & $\mathrm{M}_{6} \mathrm{~A}_{0,0 / 0,3}$ & $\mathrm{M}_{6} \mathrm{~B}_{0,0 / 0,3}$ \\
\hline 0,00 & 0,40 & $\mathrm{M} \mathrm{A}_{0,0 / 0,4}$ & $\mathrm{M} \mathrm{B}_{0,0 / 0,4}$ \\
\hline 0,00 & 0,50 & $\mathrm{M}_{8} \mathrm{~A}_{0,0 / 0,5}$ & $\mathrm{M}_{8 \mathrm{~B}_{0,0 / 0,5}}$ \\
\hline 0,60 & 0,10 & $\mathrm{M} \mathrm{A}_{0,6 / 0,1}$ & M9B $_{0,6 / 0,1}$ \\
\hline 0,60 & 0,20 & $\mathrm{M}_{10 \mathrm{~A}_{0,6 / 0,2}}$ & $\mathrm{M}_{10 \mathrm{~B}_{0,6 / 0,2}}$ \\
\hline 0,60 & 0,30 & $\mathrm{M}_{11} \mathrm{~A}_{0,6 / 0,3}$ & $\mathrm{M} 11 \mathrm{~B}_{0,6 / 0,3}$ \\
\hline 0,60 & 0,40 & $\mathrm{M}_{12 \mathrm{~A}_{0,6 / 0,4}}$ & $\mathrm{M}_{12} \mathrm{~B}_{0,6 / 0,4}$ \\
\hline 0,60 & 0,50 & $\mathrm{M}_{13} \mathrm{~A}_{0,6 / 0,5}$ & $\mathrm{M}_{13 \mathrm{~B}_{0,6 / 0,5}}$ \\
\hline 0,90 & 0,10 & $\mathrm{M}_{14 \mathrm{~A}_{0,9 / 0,1}}$ & $\mathrm{M}_{14 \mathrm{~B}_{0,9 / 0,1}}$ \\
\hline 0,90 & 0,20 & $\mathrm{M}_{15 \mathrm{~A}_{0,9 / 0,2}}$ & $\mathrm{M}_{15 \mathrm{~B}_{0,9 / 0,2}}$ \\
\hline 0,90 & 0,30 & $\mathrm{M}_{16 \mathrm{~A}_{0,9 / 0,3}}$ & $\mathrm{M}_{16 \mathrm{~B}_{0,9 / 0,3}}$ \\
\hline 0,90 & 0,40 & $\mathrm{M}_{17 \mathrm{~A}_{0,9 / 0,4}}$ & M17B $\mathrm{B}_{0,9 / 0,4}$ \\
\hline 0,90 & 0,50 & $\mathrm{M}_{18 \mathrm{~A}_{0,9 / 0,5}}$ & $\mathrm{M} 18 \mathrm{~B}_{0,9 / 0,5}$ \\
\hline
\end{tabular}

Em uma análise de dados, considera-se que não existe diferença estatisticamente significativa entre os resultados quando $\mathrm{p}>0,05$, existindo diferenças significativas quando $\mathrm{p}<0,05$. Nesse caso, aplicou-se o teste post hoc de Tukey para avaliar quais grupos são diferentes e quais são semelhantes, sendo empregadas letras sobrescritas para a identificação. Quando os resultados recebem letras sobrescritas iguais, isso indica que entre eles não existem diferenças, e quando recebem letras diferentes, significa que são estatisticamente diferentes.

\section{Resultados e discussões}

A Tabela 6 apresenta os resultados médios obtidos de ar incorporado, seguidos do desvio padrão amostral (média \pm desvio padrão), para as 36 misturas de argamassas, nos tempos de mistura 150s, 210s, 270s e 330s, com os dois tipos de agregado estudados, areia A e areia B.

Analisando-se os dados da Tabela 6 é notável que o acréscimo do AIA nas misturas incrementa consideravelmente o teor de ar incorporado nas argamassas. Com um teor de 0,1\% de AIA e tempo de mistura de 150s, independentemente de estar associado ao AEH ou não, ocorreu um aumento significativo no teor de ar incorporado nas amostras avaliadas. Isso ocorreu devido à diminuição da tensão superficial proporcionada pelo emprego do AIA, facilitando a incorporação de microbolhas de ar no interior da argamassa durante o processo de mistura.

Na Figura 4 é apresentado o teor de ar incorporado em função do tempo de mistura das argamassas com $0,0 \%$ de AIA e variando-se o aditivo AEH de 0,0\%; 0,6\% e 0,9\%, para as areias A e B, respectivamente, nas Figuras 4(a) e 4(b).

Observando-se os resultados experimentais da Figura 4 no tempo de 150s para a areia do tipo A, foi verificado nas misturas sem AIA teores de ar incorporado entre 8,9 a 10,9\% e, para as areias mais finas, do tipo B, ficou entre $11,5 \%$ a 12,2\%. Estatisticamente, para essas argamassas, não houve diferença significativa na incorporação de ar em função do tempo de mistura (p*>0,05), nem com a areia A, nem com a areia B. Pela Figura 4 também é perceptível que não houve influência significativa do AEH na incorporação de ar. Avaliando-se essas misturas com as duas granulometrias de areia (A e B) foram verificadas diferenças estatisticamente significativas $\left(\mathrm{p}^{* * *}<0,001\right)$, com diferenças de até $2,59 \%$ a mais no

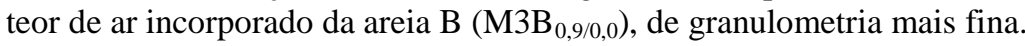

Nessas argamassas que não possuíam em sua composição o AIA a incorporação de ar deu-se unicamente pelo processo mecânico de mistura. Esse tipo de incorporação produz bolhas de ar instáveis e com alta taxa de colapsação, as quais possivelmente devam colapsar durante o período de repouso da mistura, entre os incrementos de tempo. Assim, ao serem submetidas à remistura na argamassadeira, é provável que não haja 
um efeito acumulativo de incorporação (inexistência de bolhas de ar para serem subdivididas) pelo fato de as bolhas de ar incorporadas anteriormente já haverem colapsado.

Pelas imagens de microscopia eletrônica de varredura (MEV) da Figura 5, as quais mostram a argamassa $\mathrm{M} 1 \mathrm{~A}_{0,0 / 0,0}$ com 28 dias, ampliada 120 vezes, é perceptível a baixa quantidade de poros na mistura.

Consegue-se identificar no detalhe A (ampliado 2.500x), da Figura 5, um vazio com diâmetro de 82,84 $\mu \mathrm{m}$, provável de uma bolha de ar, com fissura de retração e/ou devido ao vácuo da câmara durante o ensaio. O detalhe B (ampliado 500x) mostra a formação de bolha interna de ar isolada, com diâmetro de 394,12 $\mu \mathrm{m}$, a qual pode ter se formado simplesmente pelo processo de mistura ou por caminhos capilares interrompidos ao encontraram um grão de areia.

Na Figura 6 é apresentado o teor de ar incorporado em função do tempo de mistura para 0,1\% de AIA, variando-se o aditivo AEH de 0,0\%; $0,6 \%$ e $0,9 \%$.

Tabela 6 - Incorporação de ar das argamassas (M士DP) nos diferentes tempos de mistura analisados, para areia A e areia B

\begin{tabular}{|c|c|c|c|c|c|c|c|c|c|c|c|}
\hline \multirow{3}{*}{$\begin{array}{c}\text { Mistura } \\
\text { AEH/AIA }\end{array}$} & \multicolumn{11}{|c|}{ Ar incorporado (\%) } \\
\hline & \multicolumn{5}{|c|}{ Areia A } & \multicolumn{5}{|c|}{ Areia B } & \multirow[b]{2}{*}{$\mathbf{P} * * * *$} \\
\hline & 150s & $210 s$ & $270 s$ & 330s & $\mathbf{p}^{*}$ & 150s & $210 s$ & $270 s$ & 330s & $\mathbf{p}^{*}$ & \\
\hline $\mathbf{M 1}_{\mathbf{0 , 0 / 0 , 0}}$ & $\begin{array}{c}10,39 \pm \\
0,48\end{array}$ & $\begin{array}{c}10,74 \pm \\
0,50\end{array}$ & $\begin{array}{c}10,97 \pm \\
0,46\end{array}$ & $\begin{array}{c}11,20 \pm \\
0,38\end{array}$ & 0,218 & $\begin{array}{c}11,86 \pm \\
0,48\end{array}$ & $\begin{array}{c}12,27 \pm \\
0,33\end{array}$ & $\begin{array}{c}12,47 \pm \\
0,28\end{array}$ & $\begin{array}{c}12,76 \pm \\
0,18\end{array}$ & 0,055 & $<0,001$ \\
\hline$M 2_{0,6 / 0,0}$ & $\begin{array}{c}10,94 \pm \\
0,87\end{array}$ & $\begin{array}{c}10,87 \pm \\
0,81\end{array}$ & $\begin{array}{c}11,17 \pm \\
0,70\end{array}$ & $\begin{array}{c}11,37 \pm \\
0,73\end{array}$ & 0,856 & $\begin{array}{c}12,20 \pm \\
0,64\end{array}$ & $\begin{array}{c}12,17 \pm \\
0,44\end{array}$ & $\begin{array}{c}12,18 \pm \\
0,46\end{array}$ & $\begin{array}{c}12,75 \pm \\
0,23\end{array}$ & 0,400 & $<0,001$ \\
\hline $\mathbf{M 3}_{\mathbf{0 , 9 / 0 , 0}}$ & $\begin{array}{l}8,96 \pm \\
0,31^{\mathrm{A}}\end{array}$ & $\begin{array}{l}9,90 \pm \\
0,40^{\mathrm{AB}}\end{array}$ & $\begin{array}{l}9,98 \pm \\
0,51^{\mathrm{AB}}\end{array}$ & $\begin{array}{c}10,12 \pm \\
0,52^{\mathrm{B}}\end{array}$ & 0,043 & $\begin{array}{c}11,55 \pm \\
0,39\end{array}$ & $\begin{array}{c}11,55 \pm \\
0,62\end{array}$ & $\begin{array}{c}11,94 \pm \\
0,23\end{array}$ & $\begin{array}{c}12,11 \pm \\
0,21\end{array}$ & 0,284 & $<0,001$ \\
\hline $\mathbf{M} 4_{0,0 / 0,1}$ & $\begin{array}{c}16,17 \pm \\
1,19\end{array}$ & $\begin{array}{c}16,17 \pm \\
1,15\end{array}$ & $\begin{array}{c}16,35 \pm \\
1,09\end{array}$ & $\begin{array}{c}16,87 \pm \\
0,97\end{array}$ & 0,863 & $\begin{array}{c}18,35 \pm \\
1,36\end{array}$ & $\begin{array}{c}18,13 \pm \\
1,50\end{array}$ & $\begin{array}{c}18,68 \pm \\
1,41\end{array}$ & $\begin{array}{c}19,03 \pm \\
1,16\end{array}$ & 0,857 & $<0,001$ \\
\hline $\mathrm{M5}_{\mathbf{0}, \mathbf{0} / \mathbf{0}, 2}$ & $\begin{array}{c}20,19 \pm \\
0,87\end{array}$ & $\begin{array}{c}21,66 \pm \\
2,00\end{array}$ & $\begin{array}{c}21,70 \pm \\
2,12\end{array}$ & $\begin{array}{c}21,89 \pm \\
2,04\end{array}$ & 0,678 & $\begin{array}{c}22,96 \pm \\
1,29\end{array}$ & $\begin{array}{c}22,96 \pm \\
1,75\end{array}$ & $\begin{array}{c}23,29 \pm \\
1,50\end{array}$ & $\begin{array}{c}23,51 \pm \\
1,39\end{array}$ & 0,960 & 0,008 \\
\hline $\mathbf{M 6}_{\mathbf{0 , 0 / 0 , 3}}$ & $\begin{array}{c}25,26 \pm \\
0,74\end{array}$ & $\begin{array}{c}26,48 \pm \\
1,25\end{array}$ & $\begin{array}{c}27,44 \pm \\
0,89\end{array}$ & $\begin{array}{c}27,82 \pm \\
1,00\end{array}$ & 0,053 & $\begin{array}{c}24,49 \pm \\
0,88\end{array}$ & $\begin{array}{c}26,06 \pm \\
0,76\end{array}$ & $\begin{array}{c}26,81 \pm \\
1,10\end{array}$ & $\begin{array}{c}27,11 \pm \\
1,19\end{array}$ & 0,050 & 0,261 \\
\hline $\mathbf{M 7}_{\mathbf{0 , 0 / 0 , 4}}$ & $\begin{array}{c}25,51 \pm \\
0,90^{\mathrm{A}}\end{array}$ & $\begin{array}{c}28,21 \pm \\
0,84^{\mathrm{B}}\end{array}$ & $\begin{array}{c}29,30 \pm \\
0,89^{\mathrm{B}}\end{array}$ & $\begin{array}{c}29,98 \pm \\
0,72^{\mathrm{B}}\end{array}$ & 0,001 & $\begin{array}{c}25,55 \pm \\
0,93^{\mathrm{A}}\end{array}$ & $\begin{array}{l}27,21 \pm \\
0,87^{\mathrm{AB}}\end{array}$ & $\begin{array}{c}28,12 \pm \\
0,91^{\mathrm{B}}\end{array}$ & $\begin{array}{c}28,83 \pm \\
1,14^{\mathrm{B}}\end{array}$ & 0,016 & 0,257 \\
\hline $\mathbf{M 8}_{\mathbf{0 , 0 / 0 , 5}}$ & $\begin{array}{c}26,63 \pm \\
0,71^{\mathrm{A}}\end{array}$ & $\begin{array}{c}29,53 \pm \\
0,81^{\mathrm{B}}\end{array}$ & $\begin{array}{c}31,05 \pm \\
1,13^{\mathrm{B}}\end{array}$ & $\begin{array}{c}31,77 \pm \\
1,03^{\mathrm{B}}\end{array}$ & 0,001 & $\begin{array}{c}25,86 \pm \\
0,66^{\mathrm{A}}\end{array}$ & $\begin{array}{c}28,26 \pm \\
0,85^{\mathrm{B}}\end{array}$ & $\begin{array}{c}29,59 \pm \\
1,03^{\mathrm{B}}\end{array}$ & $\begin{array}{c}29,93 \pm \\
0,87^{\mathrm{B}}\end{array}$ & 0,002 & 0,121 \\
\hline M9 $9_{0,6 / 0,1}$ & $\begin{array}{c}20,27 \pm \\
0,72\end{array}$ & $\begin{array}{c}18,47 \pm \\
1,90\end{array}$ & $\begin{array}{c}17,78 \pm \\
1,97 \\
\end{array}$ & $\begin{array}{c}17,48 \pm \\
1,91\end{array}$ & 0,263 & $\begin{array}{c}19,47 \pm \\
1,57\end{array}$ & $\begin{array}{c}18,65 \pm \\
1,46\end{array}$ & $\begin{array}{c}18,86 \pm \\
1,41\end{array}$ & $\begin{array}{c}18,78 \pm \\
1,54\end{array}$ & 0,907 & 0,507 \\
\hline $\mathbf{M 1 0}_{0,6 / 0,2}$ & $\begin{array}{c}22,44 \pm \\
0,82\end{array}$ & $\begin{array}{c}23,09 \pm \\
1,61\end{array}$ & $\begin{array}{c}23,70 \pm \\
1,32\end{array}$ & $\begin{array}{c}24,10 \pm \\
1,44\end{array}$ & 0,465 & $\begin{array}{c}22,29 \pm \\
1,09\end{array}$ & $\begin{array}{c}22,97 \pm \\
1,31\end{array}$ & $\begin{array}{c}23,66 \pm \\
1,69\end{array}$ & $\begin{array}{c}24,23 \pm \\
1,66\end{array}$ & 0,446 & 0,934 \\
\hline M11 $_{0,6 / 0,3}$ & $\begin{array}{c}22,46 \pm \\
0,73^{\mathrm{A}} \\
\end{array}$ & $\begin{array}{l}24,41 \pm \\
0,98^{\mathrm{AB}} \\
\end{array}$ & $\begin{array}{c}25,18 \pm \\
1,15^{\mathrm{B}} \\
\end{array}$ & $\begin{array}{c}25,84 \pm \\
1,12^{\mathrm{B}} \\
\end{array}$ & $\mathbf{0 , 0 1 7}$ & $\begin{array}{c}24,38 \pm \\
0,34^{\mathrm{A}} \\
\end{array}$ & $\begin{array}{l}25,55 \pm \\
0,45^{\mathrm{AB}} \\
\end{array}$ & $\begin{array}{c}26,10 \pm \\
0,66^{\mathrm{B}} \\
\end{array}$ & $\begin{array}{c}26,38 \pm \\
0,58^{\mathrm{B}} \\
\end{array}$ & 0,007 & 0,046 \\
\hline M12 $_{0,6 / 0,4}$ & $\begin{array}{c}24,13 \pm \\
0,65^{\mathrm{A}}\end{array}$ & $\begin{array}{c}27,00 \pm \\
0,46^{\mathrm{B}}\end{array}$ & $\begin{array}{l}28,50 \pm \\
0,84^{\mathrm{BC}}\end{array}$ & $\begin{array}{c}29,30 \pm \\
0,73^{\mathrm{C}}\end{array}$ & $<0,001$ & $\begin{array}{c}24,21 \pm \\
0,28^{\mathrm{A}}\end{array}$ & $\begin{array}{c}26,40 \pm \\
0,46^{\mathrm{B}}\end{array}$ & $\begin{array}{l}27,32 \pm \\
0,57^{\mathrm{BC}}\end{array}$ & $\begin{array}{c}27,94 \pm \\
0,65^{\mathrm{C}}\end{array}$ & $<0,001$ & 0,325 \\
\hline M13 $_{0,6 / 0,5}$ & $\begin{array}{c}25,95 \pm \\
0,07^{\mathrm{A}}\end{array}$ & $\begin{array}{c}29,11 \pm \\
0,29^{\mathrm{B}}\end{array}$ & $\begin{array}{c}31,05 \pm \\
0,34^{\mathrm{C}}\end{array}$ & $\begin{array}{c}31,81 \pm \\
0,27^{\mathrm{D}}\end{array}$ & $<0,001$ & $\begin{array}{c}25,70 \pm \\
0,21^{\mathrm{A}}\end{array}$ & $\begin{array}{c}27,76 \pm \\
0,53^{\mathrm{B}}\end{array}$ & $\begin{array}{l}28,92 \pm \\
0,43^{\mathrm{BC}}\end{array}$ & $\begin{array}{c}29,40 \pm \\
0,55^{\mathrm{C}}\end{array}$ & $<0,001$ & 0,075 \\
\hline M14 $_{\mathbf{0}, \mathbf{9} / \mathbf{0}, \mathbf{1}}$ & $\begin{array}{c}20,03 \pm \\
1,24\end{array}$ & $\begin{array}{c}19,69 \pm \\
1,95\end{array}$ & $\begin{array}{c}19,51 \pm \\
2,05\end{array}$ & $\begin{array}{c}19,43 \pm \\
2,09\end{array}$ & 0,977 & $\begin{array}{c}18,65 \pm \\
1,90\end{array}$ & $\begin{array}{c}18,36 \pm \\
2,00\end{array}$ & $\begin{array}{c}18,15 \pm \\
2,06\end{array}$ & $\begin{array}{c}18,16 \pm \\
1,91\end{array}$ & 0,987 & 0,061 \\
\hline M15 $_{0,9 / 0,2}$ & $\begin{array}{c}21,30 \pm \\
1,23\end{array}$ & $\begin{array}{c}22,23 \pm \\
1,48\end{array}$ & $\begin{array}{c}22,92 \pm \\
1,27\end{array}$ & $\begin{array}{c}23,26 \pm \\
1,34 \\
\end{array}$ & 0,341 & $\begin{array}{c}21,04 \pm \\
1,11\end{array}$ & $\begin{array}{c}21,73 \pm \\
1,41 \\
\end{array}$ & $\begin{array}{c}22,14 \pm \\
1,35\end{array}$ & $\begin{array}{c}22,63 \pm \\
1,08\end{array}$ & 0,492 & 0,321 \\
\hline M16 $_{0,9 / 0,3}$ & $\begin{array}{c}22,98 \pm \\
0,80^{\mathrm{A}}\end{array}$ & $\begin{array}{c}24,70 \pm \\
1,19^{\mathrm{AB}}\end{array}$ & $\begin{array}{l}25,64 \pm \\
1,31^{\mathrm{AB}}\end{array}$ & $\begin{array}{c}26,26 \pm \\
1,48^{\mathrm{B}}\end{array}$ & 0,048 & $\begin{array}{c}22,65 \pm \\
0,79^{\mathrm{A}}\end{array}$ & $\begin{array}{l}24,46 \pm \\
0,77^{\mathrm{AB}}\end{array}$ & $\begin{array}{l}25,01 \pm \\
1,14^{\mathrm{AB}}\end{array}$ & $\begin{array}{c}25,46 \pm \\
0,89^{\mathrm{B}}\end{array}$ & 0,024 & 0,423 \\
\hline $\mathrm{M17}_{\mathbf{0 , 9 / 0 , 4}}$ & $\begin{array}{c}24,28 \pm \\
0,27^{\mathrm{A}}\end{array}$ & $\begin{array}{c}27,14 \pm \\
0,49^{\mathrm{B}}\end{array}$ & $\begin{array}{l}28,32 \pm \\
0,45^{\mathrm{BC}}\end{array}$ & $\begin{array}{c}28,85 \pm \\
0,69^{\mathrm{C}}\end{array}$ & $<0,001$ & $\begin{array}{c}24,32 \pm \\
0,46^{\mathrm{A}}\end{array}$ & $\begin{array}{c}26,47 \pm \\
0,51^{\mathrm{B}}\end{array}$ & $\begin{array}{l}27,42 \pm \\
0,60^{\mathrm{BC}}\end{array}$ & $\begin{array}{c}27,97 \pm \\
0,49^{\mathrm{C}}\end{array}$ & $<0,001$ & 0,398 \\
\hline M18 $_{\mathbf{0 , 9 / 0 , 5}}$ & $\begin{array}{c}24,77 \pm \\
0,35^{\mathrm{A}}\end{array}$ & $\begin{array}{c}28,15 \pm \\
0,50^{\mathrm{B}}\end{array}$ & $\begin{array}{c}29,92 \pm \\
0,61^{\mathrm{C}}\end{array}$ & $\begin{array}{c}30,89 \pm \\
0,57^{\mathrm{C}}\end{array}$ & $<0,001$ & $\begin{array}{c}25,33 \pm \\
0,18^{\mathrm{A}}\end{array}$ & $\begin{array}{c}27,56 \pm \\
0,37^{\mathrm{B}}\end{array}$ & $\begin{array}{c}28,67 \pm \\
0,30^{\mathrm{C}}\end{array}$ & $\begin{array}{c}29,32 \pm \\
0,29^{\mathrm{C}}\end{array}$ & $<0,001$ & 0,411 \\
\hline $\mathbf{p}^{* *}$ & $<0,001$ & $<0,001$ & $<0,001$ & $<0,001$ & - & $<0,001$ & $<0,001$ & $<0,001$ & $<0,001$ & - & - \\
\hline
\end{tabular}

Nota: Legenda:

$\mathrm{p}^{*}$ Comparações do teor de ar entre os diferentes tempos de mistura: ANOVA e post hoc de Tukey (letras diferentes: com diferenças estatisticamente significantes; letras iguais: sem diferenças estatisticamente significantes);

$\mathrm{p}^{* *}$ Comparações do teor de ar entre as diferentes misturas: ANOVA; e

$\mathrm{P}^{* * *}$ Comparações do teor de ar entre os diferentes agregados: Teste $\mathrm{T}$. 
Figura 4 - Comparativo do teor de ar incorporado pelo tempo de mistura das argamassas com mesmo $0 \%$ teor de AIA e diferentes teores de AEH, para areia A (a) e areia B (b)

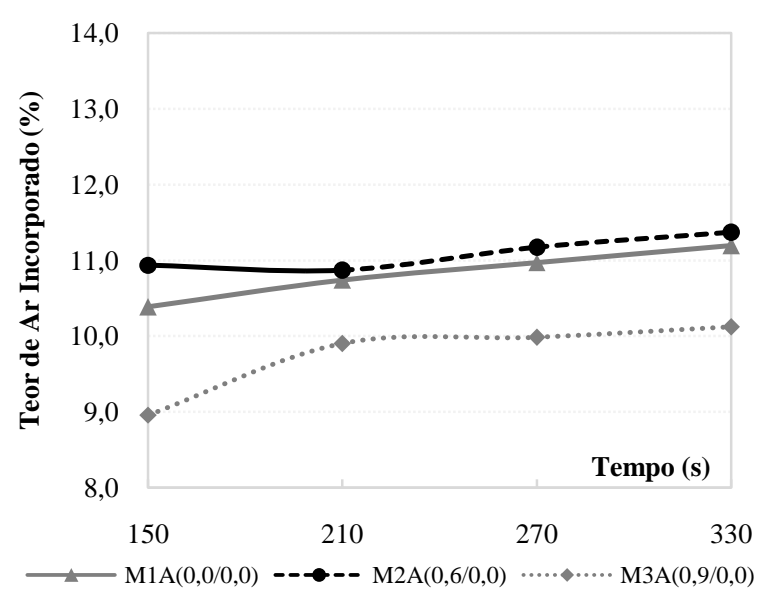

(a)

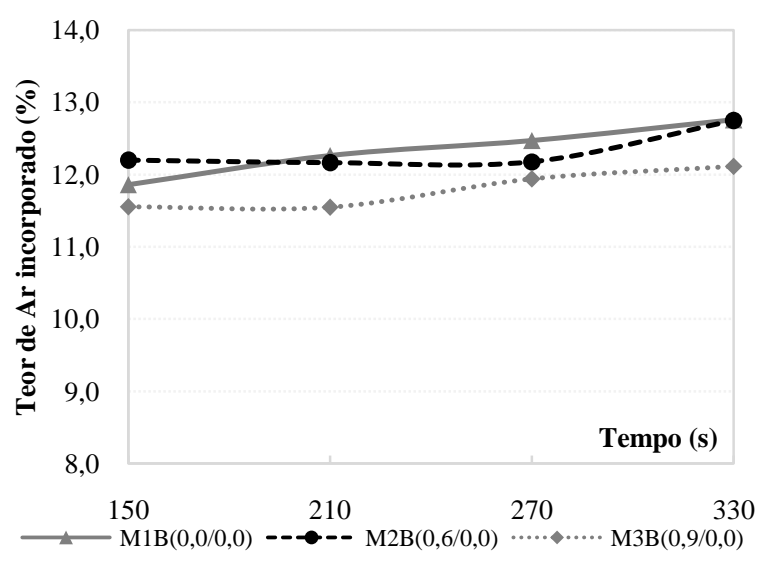

(b)

Figura 5 - Microscopia eletrônica de varredura da M1A0,0/0,0

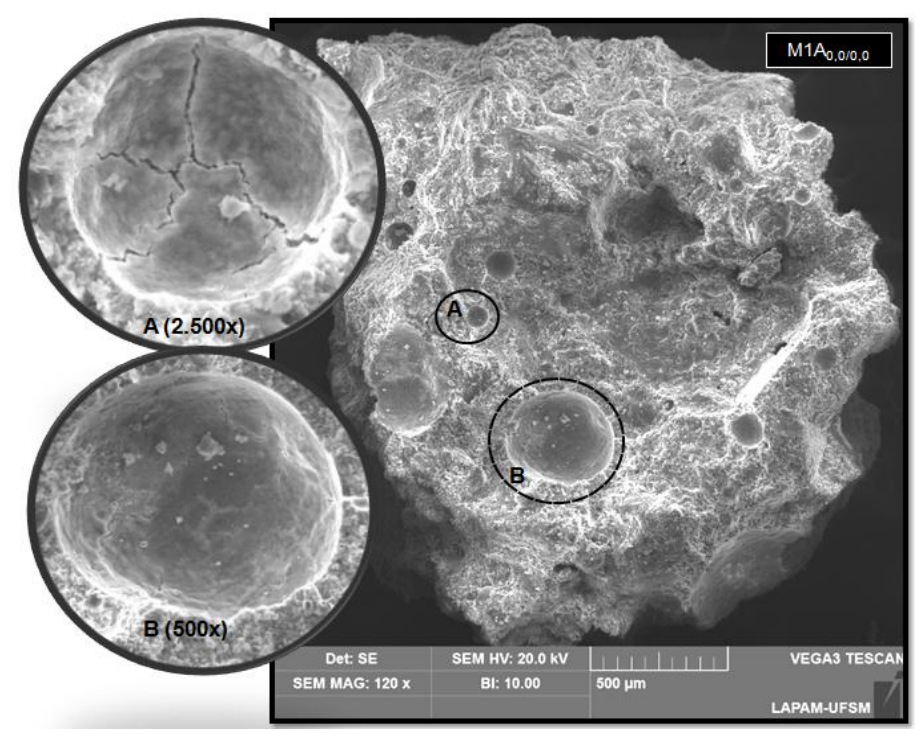

Figura 6 - Comparativo do teor de ar incorporado pelo tempo de mistura das argamassas com $0,1 \%$ teor de AIA e diferentes teores de AEH, para areia A (a) e areia B (b)

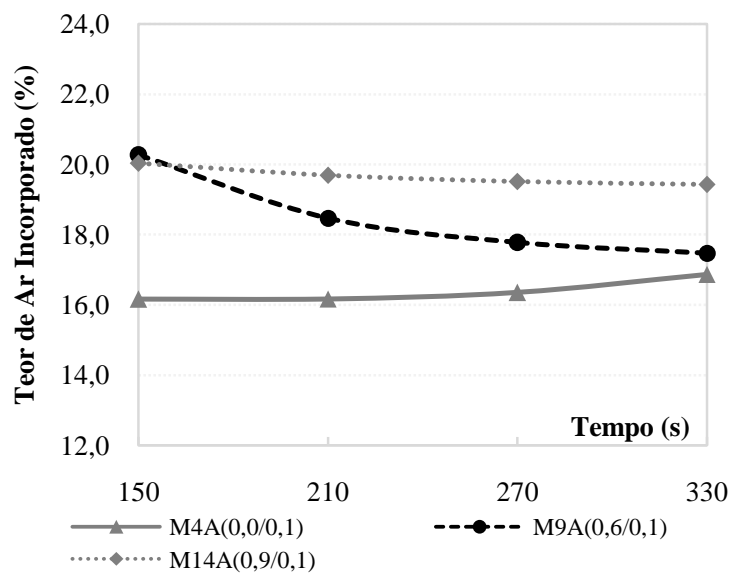

(a)

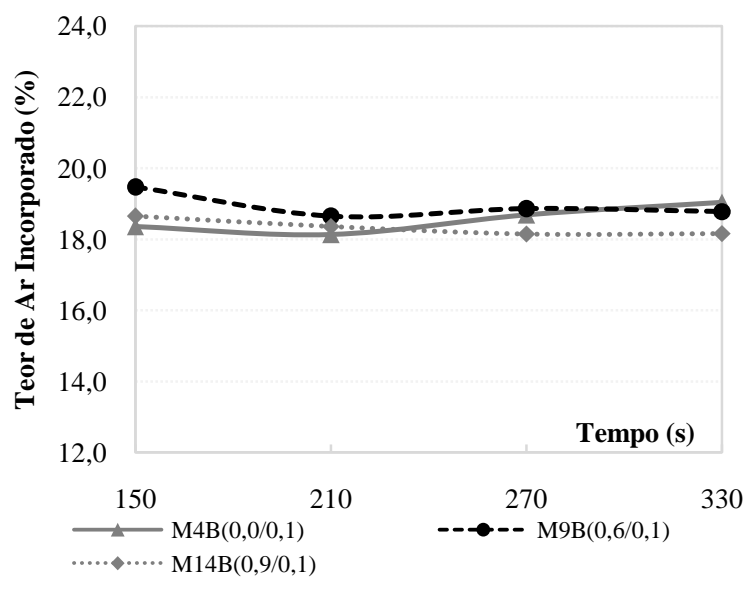

(b) 
Observando-se os resultados experimentais da Figura 6 para as areias do tipo A e B, foi verificado um aumento significativo no teor de ar incorporado em relação às misturas sem AIA, apresentadas na Figura 4,

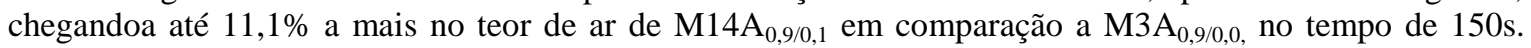
Para a areia A, observou-se um aumento de $4 \%$ inicialmente no teor de ar incorporado ao se acrescentar

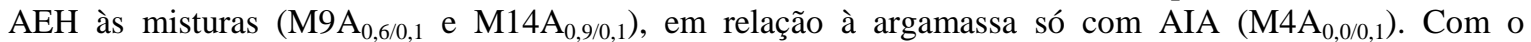
aumento do tempo de mistura a argamassa $\mathrm{M}_{0,6 / 0,1}$ apresentou tendência de diminuição do teor de ar incorporado, em valores absolutos; porém, quando analisados estatisticamente, a partir do desvio padrão amostral, não se verificou diferença significativas. Para a areia do tipo B não houve diferenças nos valores do teor de ar incorporado em função do tempo de mistura nem com o acréscimo de AEH às composições. Quando comparado o efeito das granulometrias, foram verificadas diferenças significativas apenas de $\mathrm{M}_{4} \mathrm{~A}_{0,0 / 0,1}$ para $\mathrm{M}_{4} \mathrm{~B}_{0,0 / 0,1}\left(\mathrm{p}^{* * *}<0,001\right)$, em que a areia $\mathrm{B}$, mais fina, incorporou até $2,33 \%$ a mais de ar no tempo de 270 s.

Verifica-se que o teor de AIA empregado, mesmo que ainda baixo, foi o suficiente para aumentar o teor de ar em no mínimo $6 \%$ em relação à argamassa de referência, através da redução da tensão superficial proporcionada pelas moléculas do aditivo, combinada à agitação mecânica (ROMANO, 2013). No entanto, com baixos teores de AIA provavelmente o ar seja incorporado todo no início da mistura, não sofrendo variações significativas com o aumento do tempo de cisalhamento entre as partículas.

A Figura 7 traz um comparativo para as argamassas com 0,2\% de AIA e diferentes teores de AEH, para as areias A (Figura 7a) e B (Figura 7b).

Na Figura 7 verificou-se um aumento no teor de ar incorporado para as misturas com a areia do tipo A e B em relação aos apresentados anteriormente. Quando comparado o teor de ar incorporado para as misturas variando-se o teor de AEH e para um mesmo teor de AIA de $0,2 \%$, não se verificou diferenças estatisticamente significativas com o aumento do tempo de mistura $\left(\mathrm{p}^{*}>0,05\right)$ nem com o acréscimo de AEH. Comparando-se as diferentes granulometrias de areias, foram observadas diferenças significativas $\left(\mathrm{p}^{* * *}=0,008\right)$ entre os teores de ar incorporado obtidos apenas entre as misturas $\mathrm{M}_{5} \mathrm{~A}_{0,0 / 0,2}$ e $\mathrm{M}_{5} \mathrm{~B}_{0,0 / 0,2}$ chegando a até $2,77 \%$ a mais de ar na areia $\mathrm{B}$, no tempo de 150 s.

Nota-se que houve um aumento no desvio padrão dos resultados ao longo do tempo de mistura e combinação de aditivos, o que pode ter influenciado na análise estatística das amostras ao se comparar os tempos de mistura e o tipo de areia. Assim, os coeficientes $\mathrm{p}^{*}$ e $\mathrm{p}^{* * *}$ apresentaram resultados maiores que 0,05 , demonstrando não existir diferença significativa entre os tempos de mistura para cada areia e entre as areias, exceto em $M 5_{0,0 / 0,2}\left(\mathrm{p}^{* * *}=0,008\right)$.

Figura 7 - Comparativo do teor de ar incorporado pelo tempo de mistura das argamassas com $0,2 \%$ teor de AIA e diferentes teores de AEH, para areia A (a) e areia B (b)

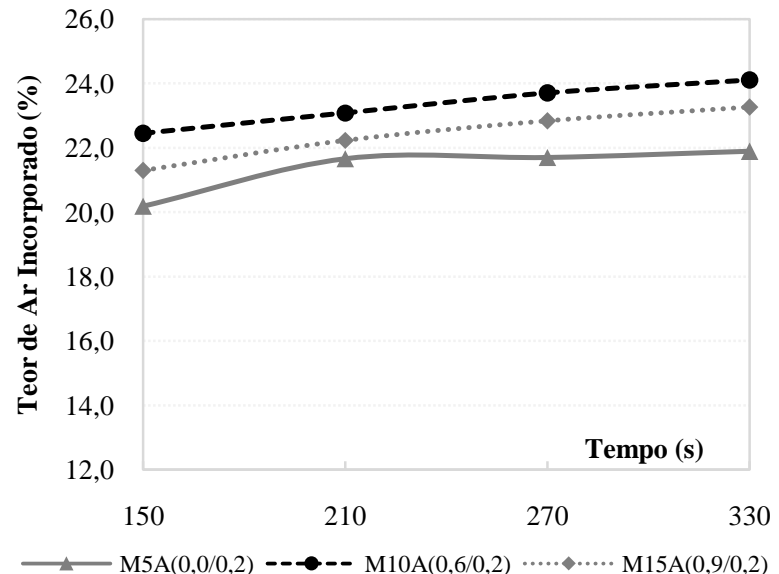

(a)

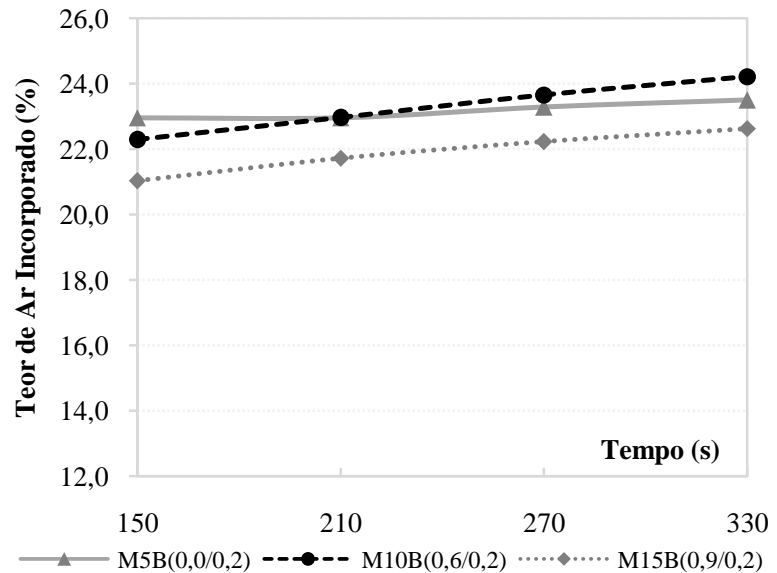

(b) 
Na Figura 8 são apresentadas as imagens via MEV da argamassa M5A $\mathrm{A}_{0,0 / 0,2}$, com $0,2 \%$ de AIA e $0,0 \%$ de $\mathrm{AEH}$, ampliada 120 vezes. Através dessas imagens percebe-se a formação de bolhas de ar significativas na mistura, condizentes com os resultados encontrados, com formato circular bem definido e em diferentes

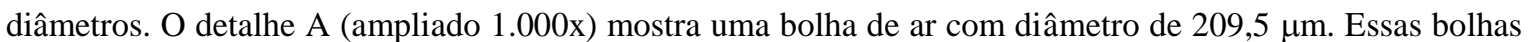
apresentam extensivas fissurações possivelmente causadas por retração, como mostra o detalhe B (ampliado 3.000x), de diâmetro 46,87 $\mu \mathrm{m}$.

Nas Figuras 9, 10 e 11, para as misturas com teores de AIA de 0,3\%; 0,4\% e 0,5\%, com diferentes teores de $\mathrm{AEH}$, foram verificados aumentos significativos $\left(\mathrm{p}^{*}<0,05\right)$ no teor de ar incorporado em relação aos tempos de mistura para os dois tipos de areias (A e B).

Figura 8 - Microscopia eletrônica de varredura da $\mathrm{MSA}_{0,0 / 0,2}$

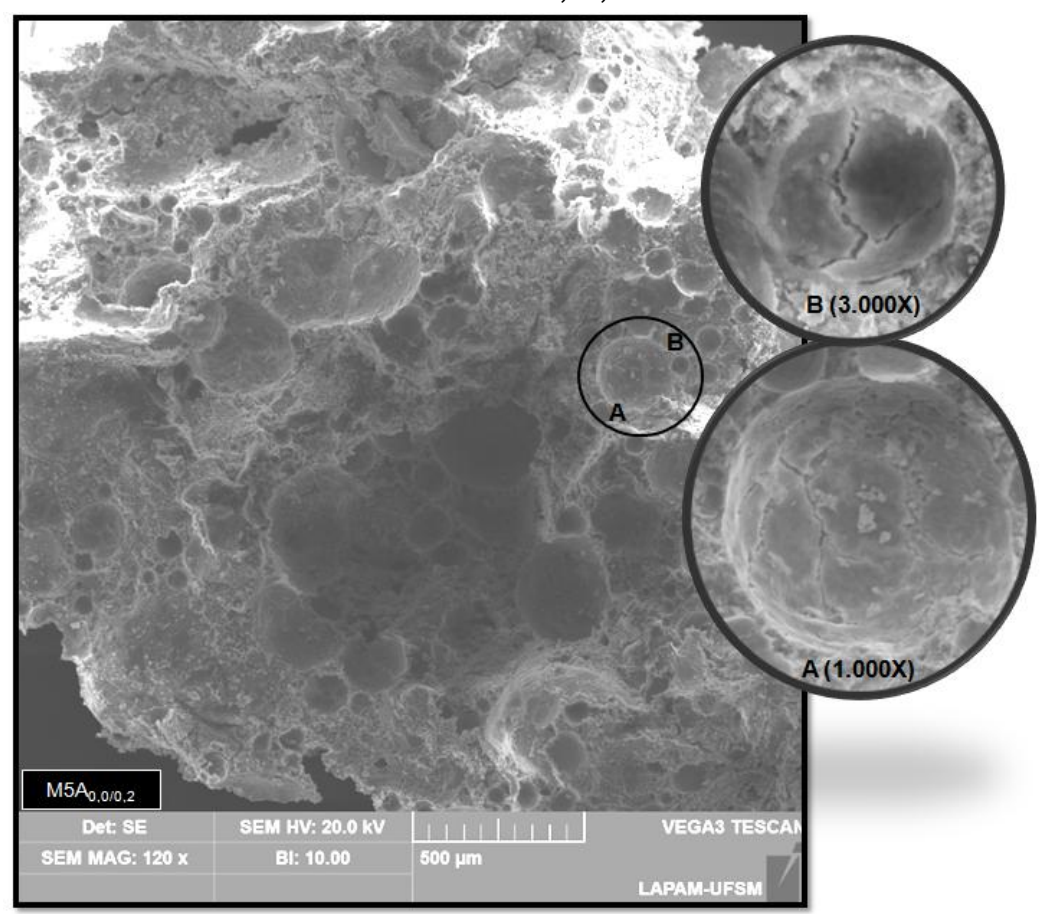

Figura 9 - Comparativo do teor de ar incorporado pelo tempo de mistura das argamassas com $0,3 \%$ teor de AIA e diferentes teores de AEH, para areia A (a) e areia B (b)

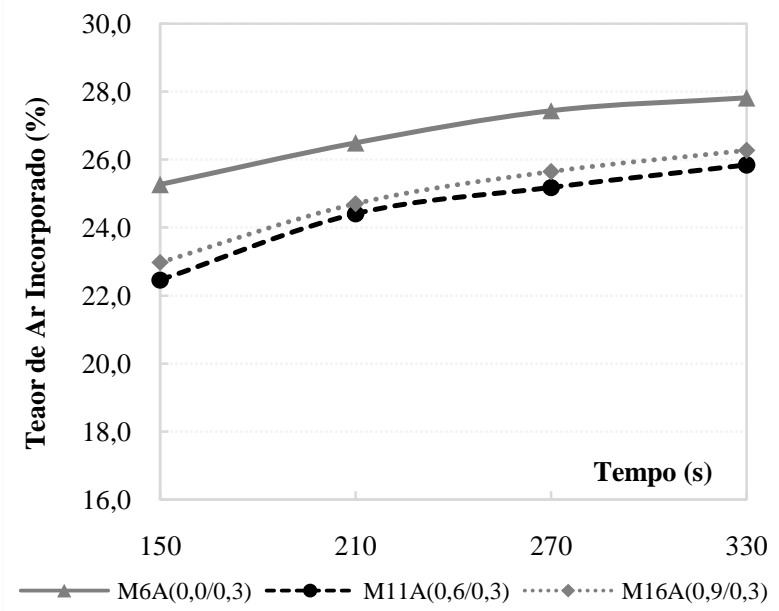

(a)

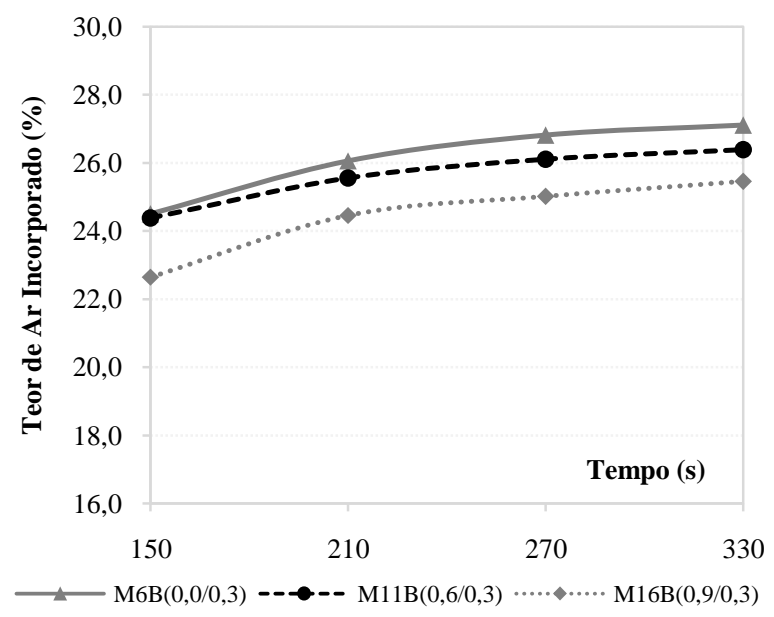

(b) 
Figura 10 - Comparativo do teor de ar incorporado pelo tempo de mistura das argamassas com $0,4 \%$ teor de AIA e diferentes teores de AEH, para areia A (a) e areia B (b)

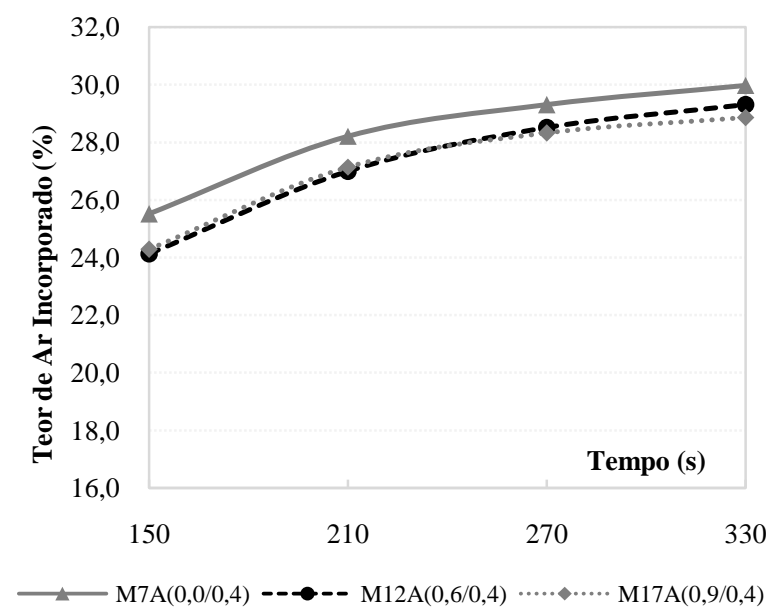

(a)

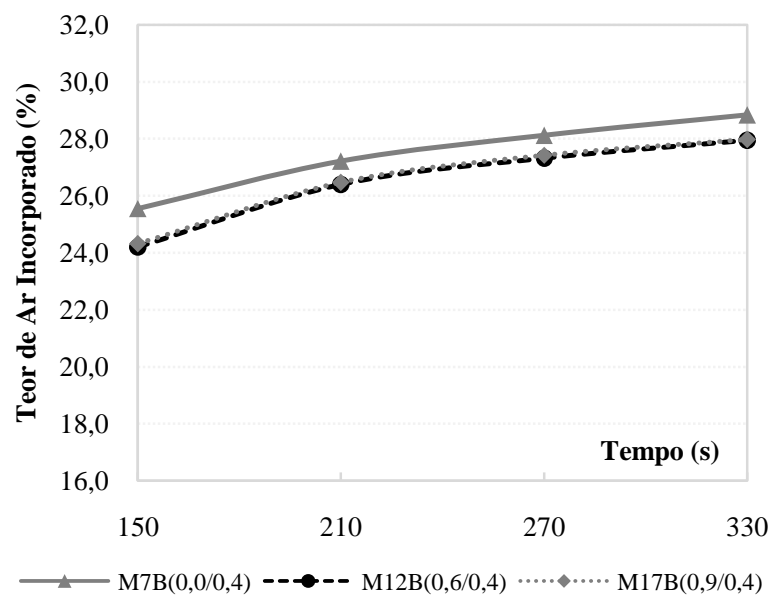

(b)

Figura 11 - Comparativo do teor de ar incorporado pelo tempo de mistura das argamassas com $0,5 \%$ teor de AIA e diferentes teores de AEH, para areia A (a) e areia B (b)

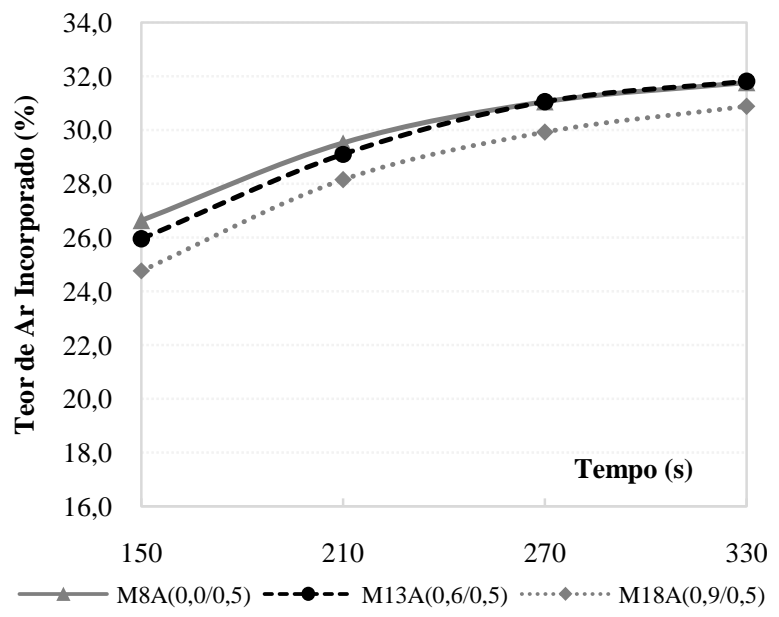

(a)

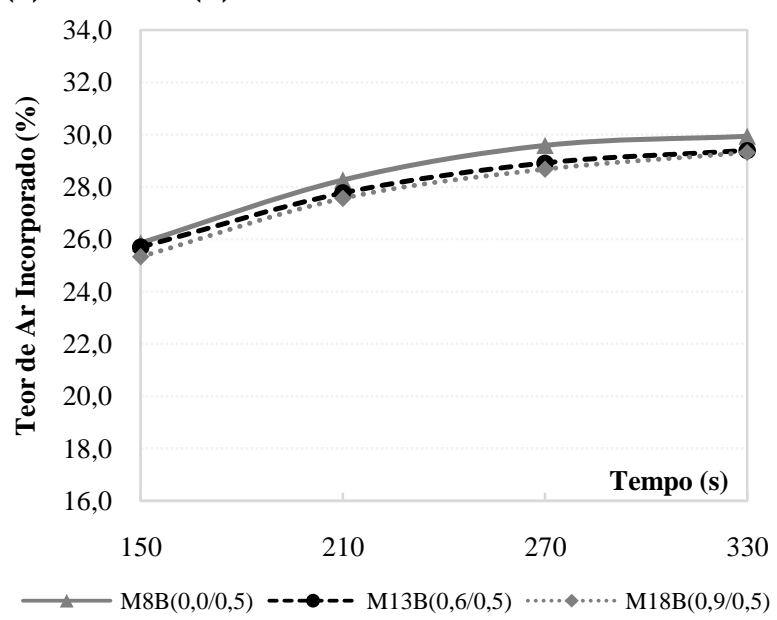

(b)

Observou-se nas Figuras 9, 10 e 11 uma mesma tendência de comportamento em que as argamassas com os dois aditivos resultaram em uma incorporação de ar inferior às argamassas somente com AIA, com diferenças mais expressivas para o teor de 0,3\% de AIA (Figura 9). Essa diminuição do teor de ar incorporado provavelmente seja devido à interferência do AEH sobre o efeito espumante do AIA. Também pode ser visualizado nas Figuras 9, 10 e 11 que com o aumento do tempo de mistura ocorre também um aumento no ar incorporado, porém acompanhado de uma diminuição do ângulo de deflexão das curvas. Essa diminuição do ângulo aponta para um limite de incorporação de ar, demonstrando que para as argamassas estabilizadas existe uma correlação direta entre ar incorporado e tempo de mistura, porém não linear. Assim, a Figura 12 exemplifica essa relação através do traçado de linhas de tendência linear $\left(\mathrm{R}^{2}=0,86\right)$ e pelo melhor ajuste polinomial $\left(\mathrm{R}^{2}=0,93\right)$.

Quando comparados os teores de ar incorporado obtidos para as areias A e B nessas misturas com 0,3\%, $0,4 \%$ e $0,5 \%$ de AIA para diferentes teores de AEH, não foram detectadas diferenças significativas $\left(\mathrm{p}^{* * *}>0,05\right)$. Nota-se, então, que para esses teores de AIA a granulometria da areia não maisinfluenciou o teor de ar incorporado em função do tempo de mistura.

Na Figura 13 é apresentada a imagem via MEV de argamassa M12 $\mathrm{A}_{0,6 / 0,4}$, com 0,4\% de AIA e 0,6\% de $\mathrm{AEH}$, ampliada 120 vezes, na qual se verifica uma extensiva formação de bolhas de ar, de diferentes diâmetros, com formatos mais irregulares e maior rugosidade da superfície interna (detalhe A, ampliado 
1.500x). É possível verificar também muitas bolhas de ar concentradas em torno do grão de agregado e a presença de vazios capilares interrompidos por esses grãos (detalhe $\mathrm{B}$, ampliado 7.000x).

Através dos resultados pode-se dizer que o uso isolado do AEH não contribuiu para o aumento da incorporação de ar nas argamassas. Nas misturas que utilizaram AIA, percebeu-se que para teores até $0,2 \%$ de AIA, a incorporação de ar com a areia A foi numericamente maior nas argamassas que combinaram AEH+AIA do que as que utilizaram apenas AIA, enquanto com a areia B permaneceu praticamente inalterada. Para teores de AIA acima de $0,3 \%$ foi observada, para as duas areias, uma tendência de diminuição da incorporação de ar para argamassas que utilizaram a combinação de AEH+AIA, quando comparado às misturas somente com AIA. Além disso, para esses teores de AIA acima de 0,3\%, todas as misturas apresentaram sensibilidade ao tempo de mistura, aumentando os teores de ar no decorrer dos incrementos de tempo, tendendo à estabilização. Ainda, pode-se constatar que, dentro das argamassas estudadas, de forma geral, quanto maior foi o teor de AEH empregado, menor foi a incorporação de ar obtida.

A Figura 14 mostra para cada tempo de mistura a incorporação de ar das argamassas frente ao aumento do teor de AIA, para cada teor de AEH empregado, sendo 0,0\% de AEH em (a) e (b), 0,6\% de AEH em (c) e (d) e $0,9 \%$ de AEH em (e) e (f), respectivamente para as areias A e B.

\section{Figura 12 - Relação entre o teor de ar incorporado e o tempo de mistura das argamassas}

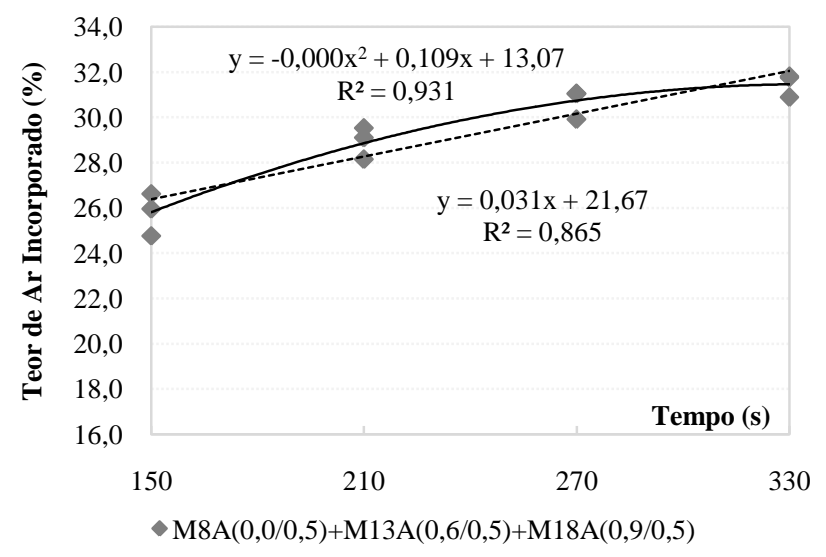

Figura 13 - Microscopia eletrônica de varredura da M12A0,6/0,4

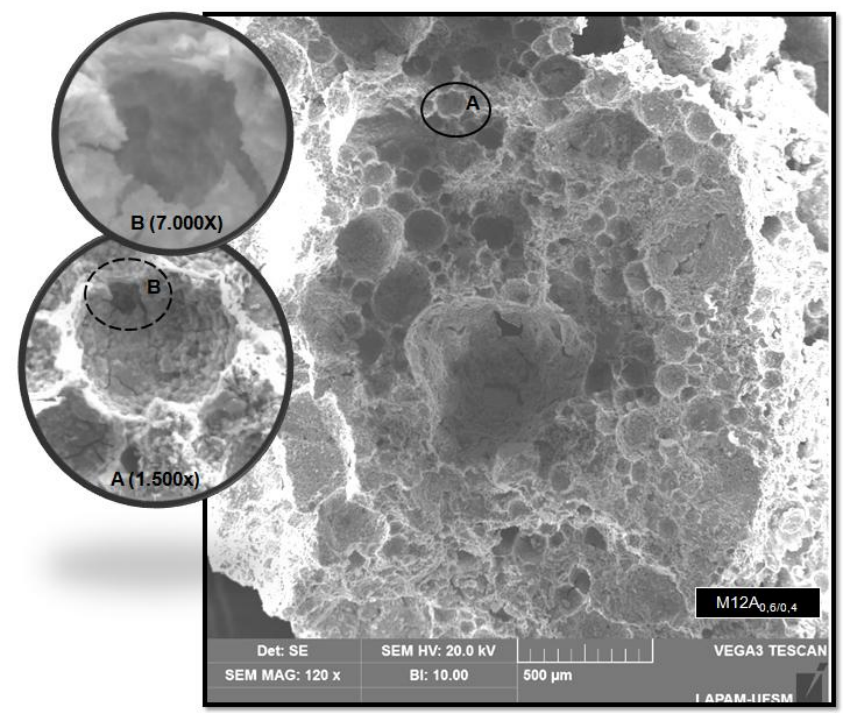


Figura 14 - Influência do tempo de mistura no teor de ar das argamassas
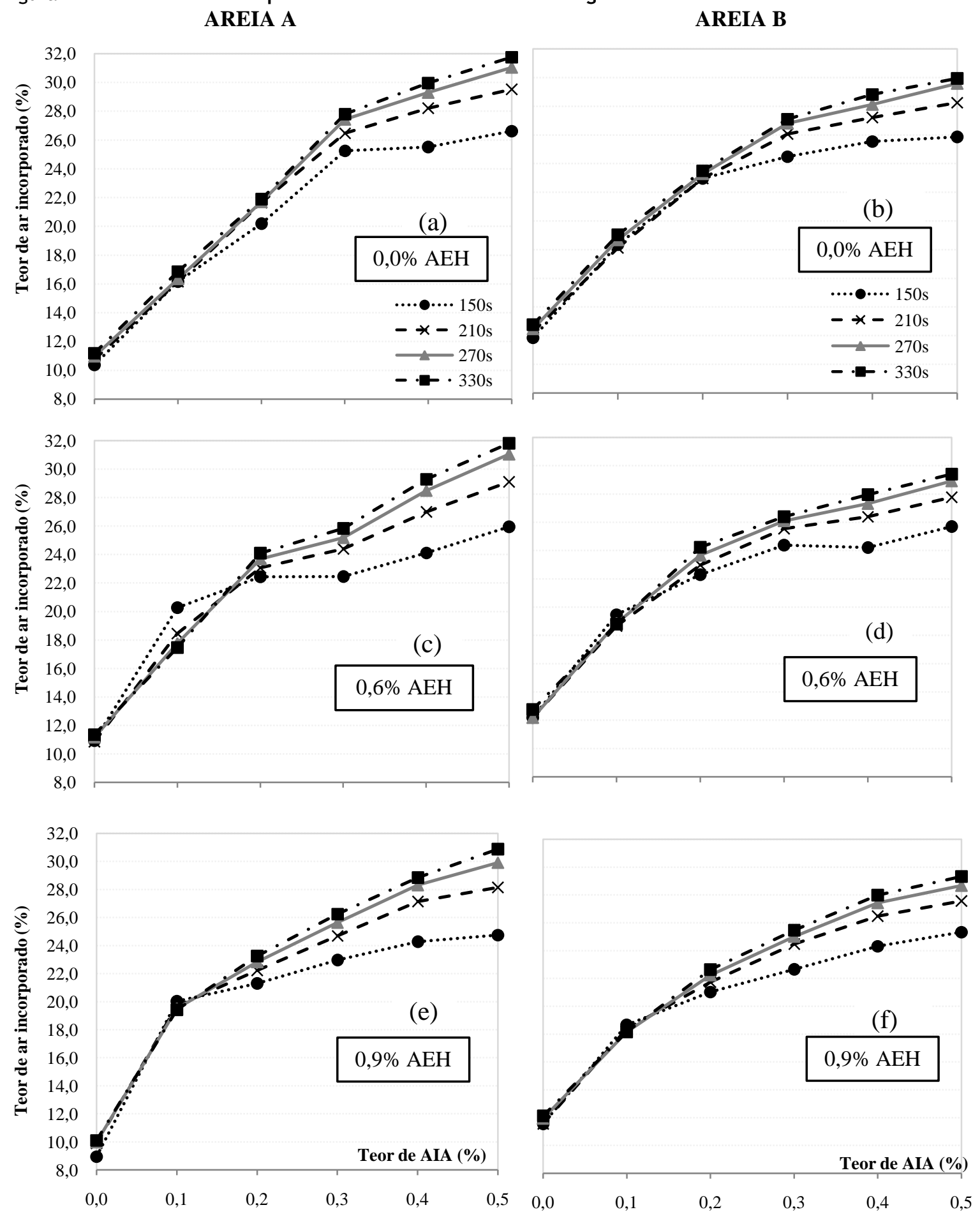

Observa-se pela Tabela 6 e Figura 14 que o tempo de mistura influenciou de forma significativa $\left(\mathrm{p}^{*}<0,05\right)$ apenas as misturas com teor de AIA acima de $0,3 \%$, mais expressivamente $\left(\mathrm{p}^{*}<0,001\right)$ para os teores de $0,4 \%$ e $0,5 \%$, independentemente do teor de AEH empregado. Verificou-se que as argamassas com $0,0 \%$, $0,1 \%$ e $0,2 \%$ de AIA, combinadas ou não ao $\mathrm{AEH}$, não sofreram influência do tempo de mistura na incorporação de ar.

Assim, em uma comparação geral entre todas as misturas de ambas as areias estudadas (ANOVA com post hoc de Tukey), verificou-se que os incrementos de tempo de mistura alteraram o teor de ar incorporado de 
forma significativa em relação ao tempo padrão de mistura a partir de 270s. Dessa forma, foi detectada uma diferença estatisticamente significativa entre o tempo de 270 s e o tempo padrão de $150 \mathrm{~s}(\mathrm{p}=0,027)$. No entanto, para o tempo de mistura de 330s não foram observadas diferenças significativas em relação ao tempo de 270s $(\mathrm{p}=0,622)$. Assim, encontrou-se o tempo de 270 s como o tempo de mistura a partir do qual a incorporação de ar se manteve praticamente constante, sendo aplicado na confecção da segunda amostra de cada mistura.

Esses resultados mostram que o tempo de mistura possui um tempo máximo de influência sobre a incorporação de ar em misturas estabilizadas, a partir do qual a incorporação de ar não é mais significativa. Assim, os comportamentos obtidos vão ao encontro dos estudos desenvolvidos por Ramachandran (1984), Beningfield (1988), Rixon e Mailvaganan (1999), que afirmam que o teor de ar incorporado atinge um ponto máximo em determinado tempo de mistura e, após isso, mesmo com a continuação da mistura, o volume de ar tende a estabilizar e/ou diminuir. No entanto, Romano et al. (2009) e Alves (2002) concluíram que as argamassas de revestimento são sensíveis ao tempo de mistura, havendo uma tendência linear de proporção direta entre a incorporação de ar e o tempo de mistura, o que talvez tenha sido por não atingirem esse tempo máximo de incorporação.

Para demonstrar a ação dos incrementos de teor de AIA na incorporação de ar, as Figuras 15, 16 e 17 a seguir agrupam as argamassas com mesmo teor de $\mathrm{AEH}$, sendo 0,0\%, 0,6\% e 0,9\%, respectivamente, variando-se os teores de AIA em $0,1 \%, 0,2 \%, 0,3 \%, 0,4 \%$ e $0,5 \%$, para a areia A (a) e areia B (b).

Figura 15 - Comparativo do ar incorporado por tempo de mistura entre argamassas com teor de $0,0 \%$ de AEH e diferentes teores de AIA, para areia A (a) e areia B (b)

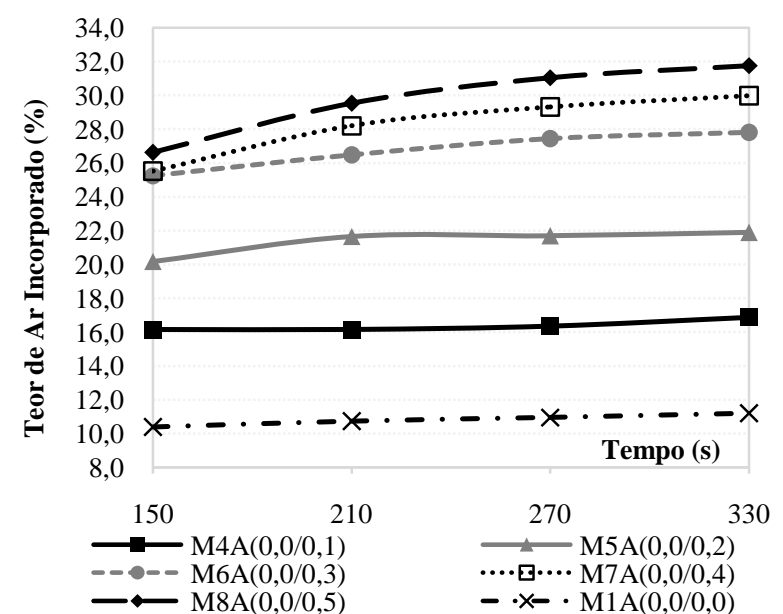

(a)

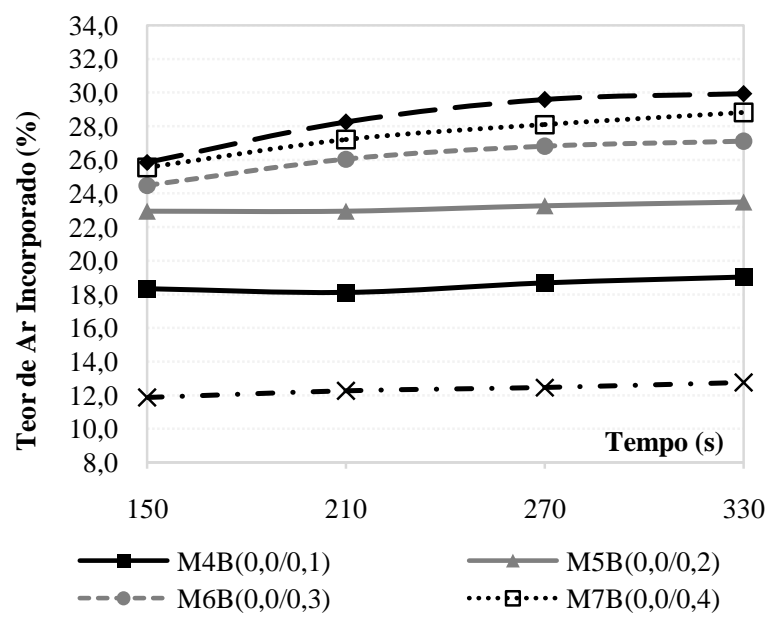

(b)

Figura 16 - Comparativo do ar incorporado por tempo de mistura entre argamassas com teor de $0,6 \%$ de AEH e diferentes teores de AIA, para areia A (a) e areia B (b)

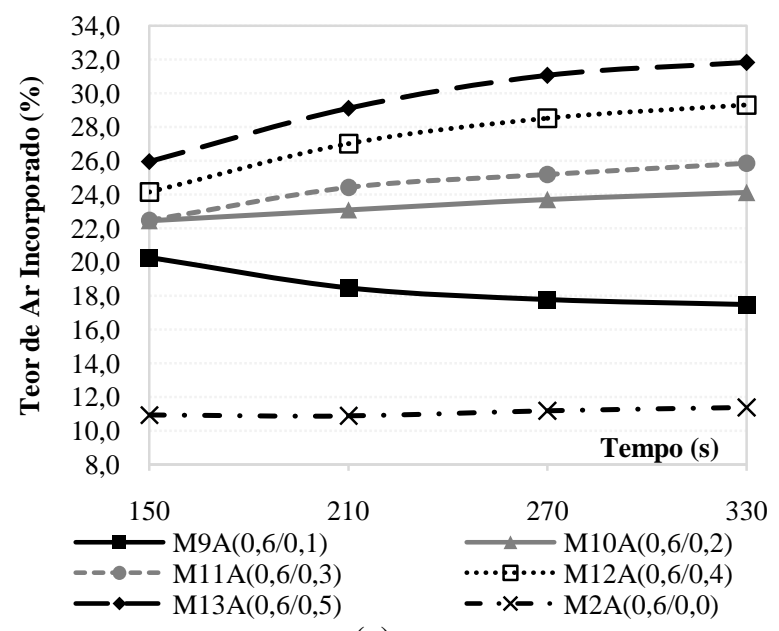

(a)

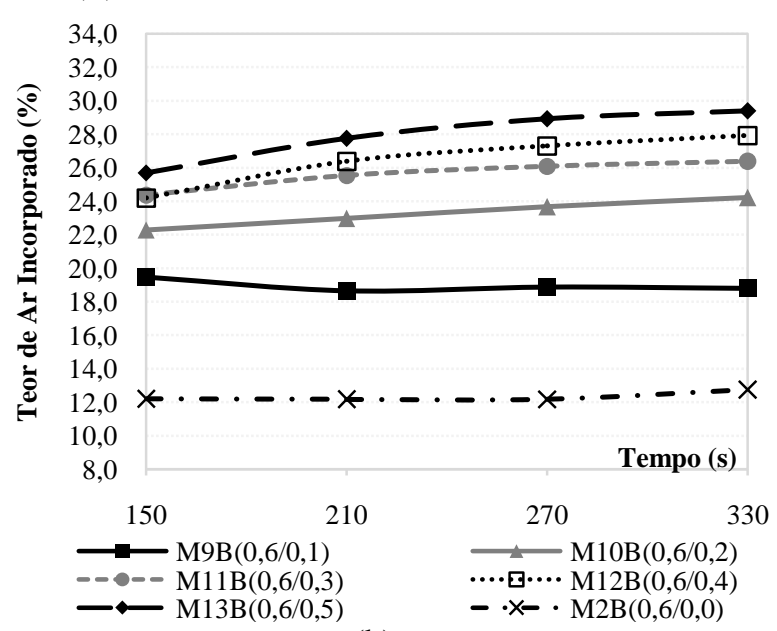

(b) 
Figura 17 - Comparativo do ar incorporado por tempo de mistura entre argamassas com teor de $0,9 \%$ de AEH e diferentes teores de AIA, para areia A (a) e areia B (b)

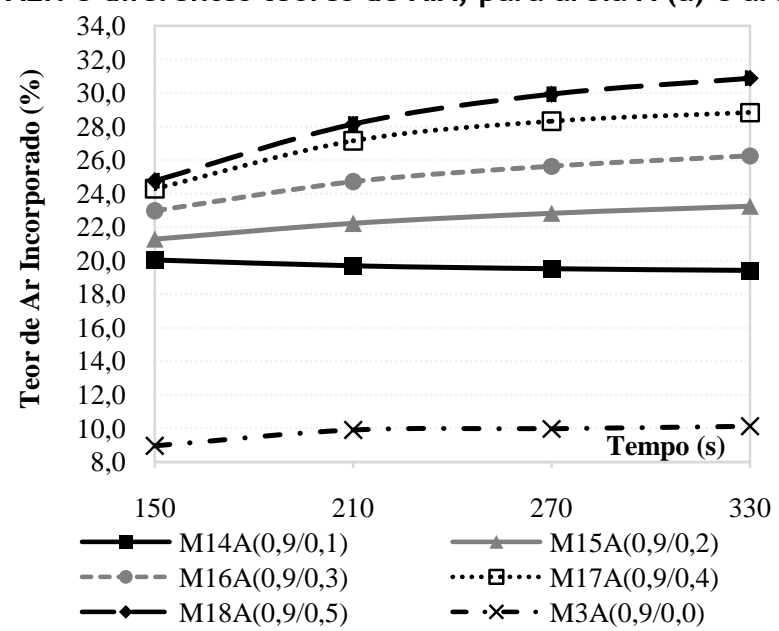

(a)

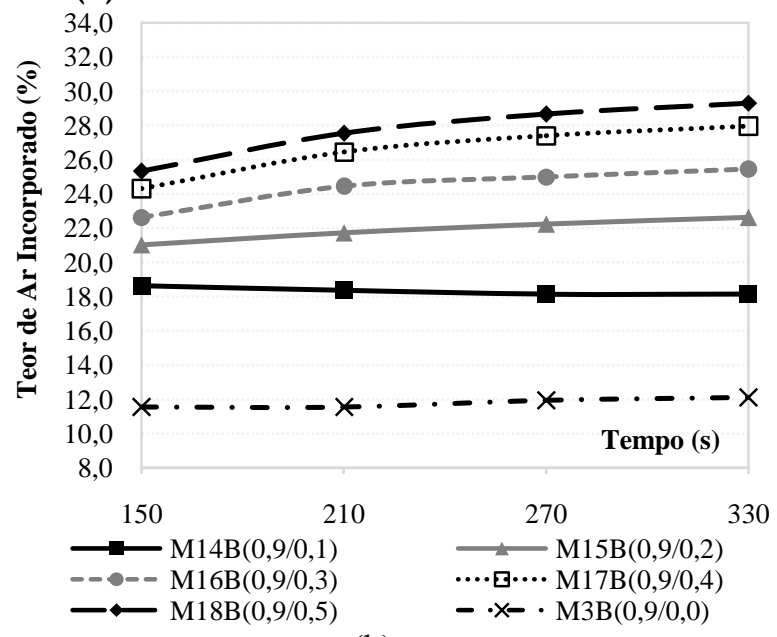

(b)

Pelas Figuras 15, 16 e 17 percebe-se que em todas as misturas a incorporação de ar aumentou com o aumento do teor de AIA empregado, porém não de forma proporcional. O aumento mais expressivo no teor de ar incorporado foi observado para teores de AIA de até 0,3\%, a partir daí passando a diminuir a diferença entre as curvas com o aumento do teor de AIA (aproximação das curvas), indicando uma tendência à estabilização do ar, mesmo com o aumento de aditivo.

Esses resultados reforçam a ideia de que exista um limite de saturação dos aditivos a partir do qual não ocorre mais aumento significativo na incorporação de ar, para um mesmo tempo e procedimento de mistura. Os resultados desta pesquisa indicam uma tendência para esse limite de AIA, possivelmente estando entre os teores de $0,3 \%$ e $0,4 \%$.

A Figura 18 apresenta as variações do teor de ar incorporado a cada incremento de tempo de mistura, para as areias A e B, agrupadas por mesmo teor de AEH. A Figura 17(a) e 17(b) agrupam as argamassas com 0,0\% de AEH e teores de $0,1 \%$ a $0,5 \%$ de AIA, respectivamente para as areias A e B. Da mesma forma, as letras 17(c) e 17(d) apresentam as argamassas com 0,6\% de AEH e teores variáveis de AIA, e as letras 17(e) e 17 (f) as misturas com $0,9 \%$ de $\mathrm{AEH}$, variando os teores de AIA.

A Figura 18 mostra para ambas as areias um comportamento similar na variação do teor de ar obtido ao longo do tempo de mistura, isto é, as variações no teor de ar incorporado diminuíram com os incrementos no tempo de mistura. Também se observou que quanto maior o teor de AIA empregado na mistura, maior foi a variação no teor de ar incorporado entre os incrementos de tempo. Consegue-se observar, ainda pela Figura 18 , que o tempo de mistura só influenciou na incorporação de ar das argamassas com teores acima de $0,3 \%$ de AIA, conforme já mostrado pelos valores da Tabela $6\left(\mathrm{p}^{*}\right)$.

Ainda pela Figura 4 e Tabela 6 é possível comparar a incorporação de ar obtida para as areias A e B, ao longo dos tempos de mistura estudados. Pela Tabela 6 percebe-se que houve diferenças estatisticamente significativas $\left(\mathrm{p}^{* * *<0,05)}\right.$ entre os resultados de teor de ar incorporado obtidos com os dois tipos de areias apenas para as misturas sem AIA ( $\mathrm{M}_{0,0 / 0,0}, \mathrm{M} 2_{0,6 / 0,0}$ e $\left.\mathrm{M}_{0,9 / 0,0}\right)$ e misturas com AIA isolado em até $0,2 \%$ $\left(\mathrm{M} 4_{0,0 / 0,1}\right.$ e $\left.\mathrm{M} 5_{0,0 / 0,2}\right)$. Nessas misturas a incorporação de ar com a utilização da areia B foi em média $2 \%$ superior à obtida com a areia $\mathrm{A}$. Ocorre que a areia $\mathrm{B}$, mesmo com granulometria mais fina, possui distribuição granulométrica mais uniforme, o que propicia maior incorporação de ar devido à maior quantidade de vazios existentes entre os agregados. A mistura M11, $10 / 0,3$ apresentou $\mathrm{p}^{* * *}$ de 0,046 , demonstrando diferença entre as areias, porém o coeficiente ficou muito próximo de não ser significativo.

Da mistura $\mathrm{M6}_{0,0 / 0,3}$ em diante pode-se constatar uma inversão de comportamentos, passando a não mais haver diferenças estatisticamente significativas $\left(\mathrm{p}^{* * *}>0,05\right)$ entres as diferentes granulometrias. Esse comportamento passou a ser observado à medida que o teor mais elevado de AIA propiciou maior quantidade de bolhas de ar incorporado e, assim, preencheu os vazios deixados pela granulometria mais uniforme da areia B. Assim, as argamassas com a areia A, constituída de grãos maiores, passaram a demonstrar potencial de incorporação de ar levemente superior às da areia B, especialmente para os teores de $0,4 \%$ e $0,5 \%$, ao longo dos diferentes tempos de mistura. Romano, Torres e Pileggi (2015) também não 
obtiveram diferenças em suas análises no teor de ar incorporado com diferentes granulometrias para argamassas aditivadas com AIA.

Com o intuito de validar os resultados das argamassas ensaiadas com incrementos de tempo de mistura e avaliar o efeito das pausas durante esse processo, foi confeccionada uma segunda amostra de cada argamassa, a qual foi misturada ininterruptamente por 270s. Os resultados das médias obtidas por mistura, seguidas do desvio padrão, considerando os dois tipos de areia, estão apresentados na Tabela 7.

Através dos resultados da Tabela 7 percebe-se que na maioria das argamassas obteve-se a segunda amostra com incorporação de ar ligeiramente inferior à primeira (obtida com pausas). A análise estatística apontou diferenças significativas $(\mathrm{p}<0,05)$ entre a primeira e a segunda amostra apenas nas argamassas $\mathrm{M6}_{0,0 / 0,3} \mathrm{e}$ $\mathrm{M} 7_{0,0 / 0,4}$, que receberam somente o AIA nos teores de $0,3 \%$ e $0,4 \%$, respectivamente. Dessa forma, os resultados obtidos na segunda amostra validam os dados obtidos na primeira amostra, podendo-se dizer que, neste estudo, as pausas durante o processo de mistura (incrementos de tempo) não interferiram na incorporação de ar das argamassas.

Figura 18 - Variação do teor de ar por incremento de tempo de mistura

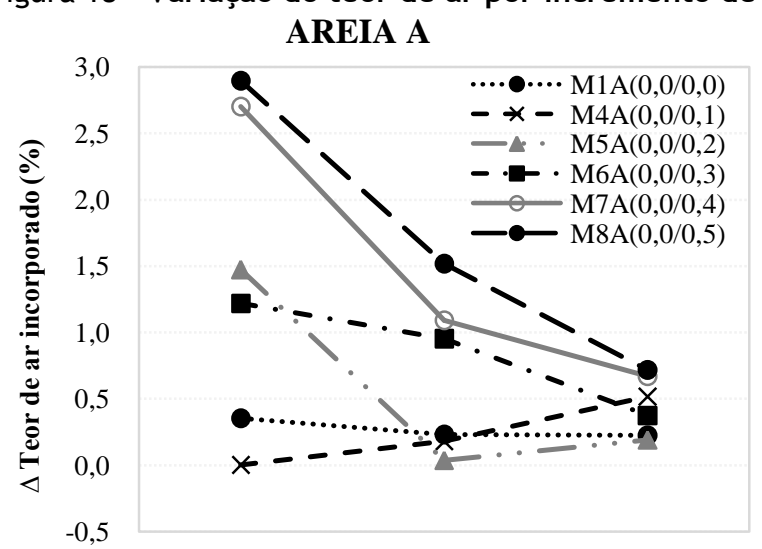

(a)

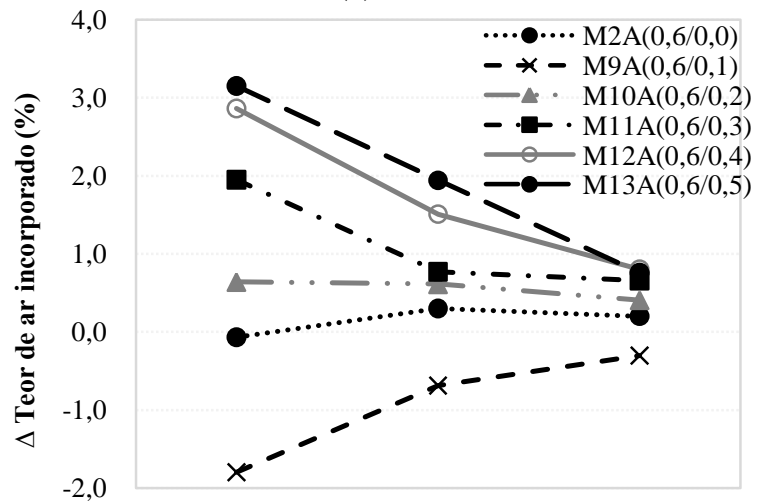

(c)

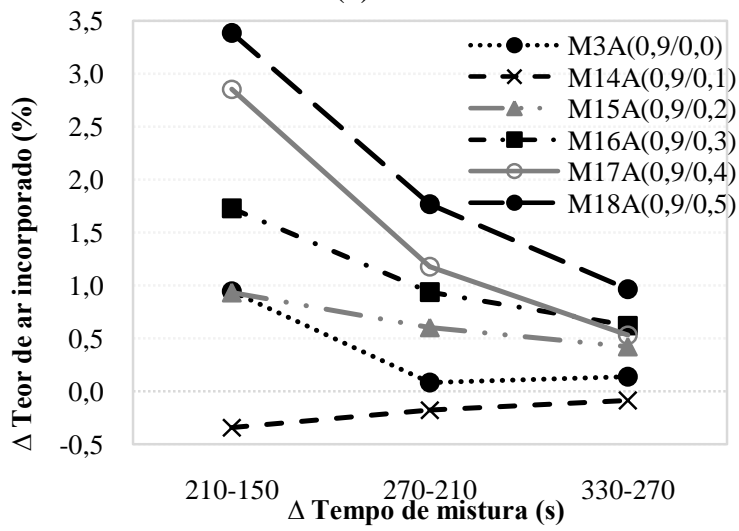

(e)

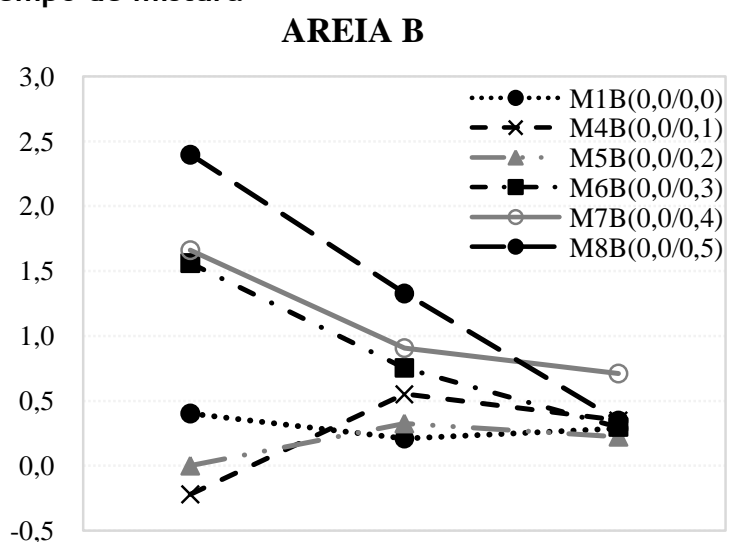

(b)

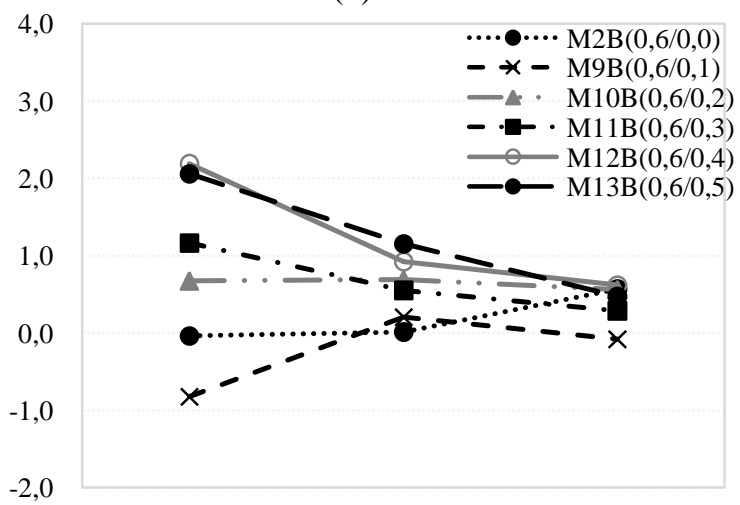

(d)

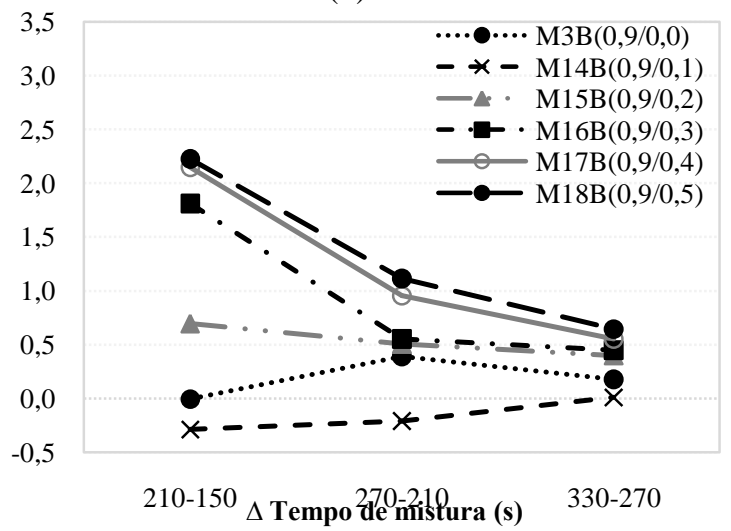

(f) 
Tabela 7 - Comparação do teor de ar incorporado entre amostras 1 e 2 para tempo de mistura de 270s

\begin{tabular}{|c|c|c|c|}
\hline \multirow[t]{2}{*}{ Mistura } & \multicolumn{2}{|c|}{ Teor de ar incorporado (\%) } & \multirow[t]{2}{*}{$\mathbf{p}$} \\
\hline & Média AM1 & Média AM2 & \\
\hline $\mathrm{M} 1_{0,0 / 0,0}$ & $11,72 \pm 0,89$ & $10,97 \pm 1,53$ & 0,481 \\
\hline $\mathrm{M} 2_{0,6 / 0,0}$ & $11,68 \pm 0,76$ & $11,06 \pm 0,73$ & 0,361 \\
\hline $\mathrm{M} 3_{0,9 / 0,0}$ & $10,96 \pm 1,13$ & $10,25 \pm 1,52$ & 0,536 \\
\hline $\mathrm{M} 4_{0,0 / 0,1}$ & $17,52 \pm 1,70$ & $16,38 \pm 1,43$ & 0,403 \\
\hline $\mathrm{M} 5_{0,0 / 0,2}$ & $22,49 \pm 1,86$ & $22,45 \pm 1,37$ & 0,903 \\
\hline $\mathrm{M6}_{0,0 / 0,3}$ & $27,12 \pm 0,96$ & $25,31 \pm 1,28$ & 0,019 \\
\hline $\mathrm{M}_{0,0 / 0,4}$ & $28,71 \pm 1,03$ & $26,65 \pm 2,33$ & 0,050 \\
\hline $\mathrm{M} 8_{0,0 / 0,5}$ & $30,32 \pm 1,25$ & $30,58 \pm 0,63$ & 0,655 \\
\hline $\mathrm{M} 9_{0,6 / 0,1}$ & $18,32 \pm 1,64$ & $18,66 \pm 1,50$ & 0,913 \\
\hline $\mathrm{M} 10_{0,6 / 0,2}$ & $23,68 \pm 1,36$ & $22,56 \pm 1,11$ & 0,519 \\
\hline $\mathrm{M} 11_{0,6 / 0,3}$ & $25,64 \pm 0,98$ & $24,79 \pm 1,00$ & 0,167 \\
\hline M12 $20,6 / 0,4$ & $27,91 \pm 0,91$ & $27,85 \pm 1,37$ & 0,557 \\
\hline M13 $30,6 / 0,5$ & $29,98 \pm 1,22$ & $29,95 \pm 1,49$ & 0,450 \\
\hline $\mathrm{M} 14_{0,9 / 0,1}$ & $18,83 \pm 1,98$ & $19,36 \pm 1,99$ & 0,776 \\
\hline $\mathrm{M} 15_{0,9 / 0,2}$ & $22,53 \pm 1,25$ & $21,74 \pm 1,23$ & 0,754 \\
\hline $\mathrm{M} 16_{0,9 / 0,3}$ & $25,33 \pm 1,15$ & $24,44 \pm 0,93$ & 0,175 \\
\hline $\mathrm{M} 17_{0,9 / 0,4}$ & $27,87 \pm 0,68$ & $27,40 \pm 0,70$ & 0,161 \\
\hline M18 $0,9 / 0.5$ & $29,30 \pm 1,47$ & $28,04 \pm 1,76$ & 0,064 \\
\hline
\end{tabular}

Nota: $\mathrm{p}=$ Teste $\mathrm{T}$.

\section{Conclusão}

O estudo avaliou a ação dos aditivos, da granulometria do agregado e do tempo de mistura na incorporação de ar de argamassas estabilizadas, e, por meio dos resultados, conclui-se que:

(a) tanto o tempo de mistura quanto o teor de AIA possuem valores limites, a partir dos quais não são obtidos mais ganhos significativos no teor de ar incorporado nas argamassas. Para as argamassas estudadas chegou-se a um valor de 270s como tempo máximo de mistura na argamassadeira para uma maior incorporação de ar. Já para o teor de AIA os resultados apontaram para um limite localizado entre os teores de $0,3 \%$ e $0,4 \%$;

(b) o tempo de mistura influenciou o comportamento das argamassas quanto à incorporação de ar apenas para teores de AIA a partir de $0,3 \%$ da massa de cimento;

(c) o uso isolado do AEH não contribuiu para a incorporação de ar nem demonstrou sensibilidade ao tempo de mistura. Quando associado ao AIA, apresentou leve tendência de diminuição do teor de ar incorporado, comparando-se às misturas apenas com AIA em igual teor;

(d) a granulometria do agregado influenciou de forma significativa a incorporação de ar apenas das argamassas sem AIA e com AIA em baixos teores (até 0,2\%). Para esses casos foram verificadas diferenças de aproximadamente $2 \%$ a mais de ar incorporado para a areia $\mathrm{B}$, com granulometria mais uniforme e módulo de finura inferior. Para as demais argamassas obteve-se teor de ar incorporado levemente superior para a areia $\mathrm{A}$, porém estatisticamente não foram detectadas diferenças entre essas argamassas; e

(e) as pausas do processo de mistura proporcionadas pelo ensaio com incrementos de tempo de mistura não interferiram na incorporação final de ar das argamassas, apresentando valores estatisticamente semelhantes aos obtidos com a mistura sem pausas.

\section{Referências}

ALVES, N. J. D. Avaliação dos aditivos incorporadores de ar em argamassas de revestimento. Brasília, 2002. Dissertação (Mestrado em Engenharia Civil) - Universidade de Brasília, Brasília, 2002.

ANTONIAZZI, J. P. et al. Avaliação do efeito dos aditivos estabilizador de hidratação e incorporador de ar em pastas de cimento portland. In: SIMPÓSIO BRASILEIRO DE TECNOLOGIA DAS ARGAMASSAS, 13., Goiânia, 2019. Anais [...] Goiânia, 2019.

ARAUJO, M. J. S. Influência do teor de aditivo aerante nas propriedades das argamassas fluidas à base de cimento. Florianópolis, 2005. Dissertação (Mestrado em Engenharia Civil) - Escola de Engenharia, Universidade Federal de Santa Catarina, Florianópolis, 2005. 
ASSOCIAÇÃO BRASILEIRA DE NORMAS TÉCNICAS. NBR 11579: cimento Portland: determinação do índice de finura por meio da peneira $75 \mu \mathrm{m}\left(\mathrm{n}^{\circ} 200\right)$. Rio de Janeiro, 2013.

ASSOCIAÇÃO BRASILEIRA DE NORMAS TÉCNICAS. NBR 11582: cimento Portland: determinação da expansibilidade Le Chatelier. Rio de Janeiro, 2016.

ASSOCIAÇÃO BRASILEIRA DE NORMAS TÉCNICAS. NBR 13278:argamassa para assentamento e revestimento de paredes e tetos: determinação da densidade de massa e do teor de ar incorporado. Rio de Janeiro, 2005.

ASSOCIAÇÃO BRASILEIRA DE NORMAS TÉCNICAS. NBR 16605: cimento Portland e outros materiais em pó: determinação da massa específica. Rio de Janeiro, 2017.

ASSOCIAÇÃO BRASILEIRA DE NORMAS TÉCNICAS. NBR 16606: cimento Portland: determinação da pasta de consistência normal. Rio de Janeiro, 2018a.

ASSOCIAÇÃO BRASILEIRA DE NORMAS TÉCNICAS. NBR 16607: cimento Portland: determinação dos tempos de pega. Rio de Janeiro, 2018 b.

ASSOCIAÇÃO BRASILEIRA DE NORMAS TÉCNICAS. NBR 7215:cimento Portland: determinação da resistência à compressão de corpos de prova cilíndricos. Rio de Janeiro, 2019.

ASSOCIAÇÃO BRASILEIRA DE NORMAS TÉCNICAS. NBR NM 14: cimento Portland: análise química: método de arbitragem para determinação de dióxido de silício, óxido férrico, óxido de alumínio, óxido de cálcio e óxido de magnésio. Rio de Janeiro, $2012 b$.

ASSOCIAÇÃO BRASILEIRA DE NORMAS TÉCNICAS. NBR NM 16: cimento Portland: análise química - determinação de anidrido sulfúrico. Rio de Janeiro, 2012c.

ASSOCIAÇÃO BRASILEIRA DE NORMAS TÉCNICAS. NBR NM 18: cimento Portland: análise química - determinação de perda ao fogo. Rio de Janeiro, 2012a.

ASSOCIAÇÃO BRASILEIRA DE NORMAS TÉCNICAS. NBR NM 22: cimento Portland com adições de materiais pozolânicos : análise química: método de arbitragem. Rio de Janeiro, 2012d.

ASSOCIAÇÃO BRASILEIRA DE NORMAS TÉCNICAS. NBR NM 248: agregados: determinação da composição granulométrica. Rio de Janeiro, 2003a.

ASSOCIAÇÃO BRASILEIRA DE NORMAS TÉCNICAS. NBR NM 45: agregados: determinação da massa unitária e do volume de vazios. Rio de Janeiro, 2006.

ASSOCIAÇÃO BRASILEIRA DE NORMAS TÉCNICAS. NBR NM 46: agregados: determinação do material fino que passa através da peneira $75 \mathrm{um}$, por lavagem. Rio de Janeiro, 2003b.

ASSOCIAÇÃO BRASILEIRA DE NORMAS TÉCNICAS. NBR NM 52: agregado miúdo: determinação da massa específica e massa específica aparente. Rio de Janeiro, 2009.

BAUER, E.; OLIVEIRA, V.C. Comportamentos e propriedades das argamassas estabilizadas de revestimentos. In: SIMPÓSIO BRASILEIRO DE TECNOLOGIA DAS ARGAMASSAS, 12., São Paulo, 2017. Anais [...] São Paulo, 2017.

BENINGFIELD, N. Air entrainment of mortar.In: INTERNATIONAL BRICK/BLOCK MASONRY CONFERENCE IRELAND, 8., Warwickshire, 1988. Proceedings [...]W Warwickshire, 1998.

FERRARIS, C. F.; OBLA, K. H.; HILL, R.The influence of mineral admixtures on the rheology of cement paste and concrete. Cement and Concrete Research, Kidlington, v. 31, n. 2, p. 245-255, 2001.

HADDAD, L.D. et al.Análise da influência da granulometria do agregado miúdo nas propriedades mecânicas e de durabilidade das argamassas de revestimento.Science \& Engineering Journal, v. 25, n.1, p. 07-16, 2016.

HARTMANN, C. et al. Aditivos químicos para concretos e cimentos. In: ISAIA, G. C. (ed.). Concreto: ciência e tecnologia. São Paulo: Ibracon, 2011.

MEHTA, P. K.; MONTEIRO, P. J. M. Concreto: microestrutura, propriedades e materiais. 2. ed. São Paulo: Ibracon, 2014.

NELSON, R. L. et al. Ready mix mortar in the United States. In: INTERNATIONAL BRICK AND BLOCK MASONRYCONFERENCE, 8., Dublin, 1988. Proceedings [...] Dublin, 1988. 
PAOLINI, M.; KHURANA, R. Admixtures for recycling of waste concrete.Cement and concrete composites, v. 20, p. 221-229, 1998.

RAMACHANDRAN, V. S. Concrete admixtures handbook. New York:Noyes Publications, 1984.

RICKERT, J.; THIELEN, G. Influence of a long-term retarders on the hydration of clinker and cement.Cement, Concrete and Aggregates, v. 26, n. 2, p. 1-10, 2004.

RIXON, R.; MAILVAGANAM, N. Chemical admixtures for concrete. London: E\&FN SPON, 1999.

ROMANO, R. C. O. et al. Impacto do tipo de misturador e do tempo de mistura nas propriedades de argamassas industrializadas. Ambiente Construído, Porto Alegre, v. 9, n. 4, p. 109-118, out./dez, 2009.

ROMANO, R.C.O. Incorporação de ar em materiais cimentícios aplicadas em construção civil. São Paulo, 2013. Tese (Doutorado em Engenharia Civil) - Escola Politécnica, Universidade de São Paulo, São Paulo, 2013.

ROMANO, R. C. O.; CINCOTTO, M. A.; PILEGGI, R. G. Incorporação de ar em materiais cimentícios: uma nova abordagem para o desenvolvimento de argamassas de revestimento. Ambiente Construído, Porto Alegre, v. 18, n. 2, p. 289-308, abr./jun. 2018.

ROMANO, R. C. O.; TORRES, D. R.; PILEGGI, R. G. Impact of aggregate grading and air-entrainment on the properties of fresh and hardened mortars. Construction and Building Materials, v. 8, p. 219-226, 2015.

SALAGER, J. L. Surfactantes em solucion acuosa. Cuaderno FIRP, Universidade de los Andes, Merida, Venezuela, p. 1-28, 1993. Polígrafo didático.

SALAGER, J. L. Surfactantes - typos y usos. Cuaderno FIRP, Universidade de los Andes, Merida, Venezuela, p. 1-54, 2002. Polígrafo didático.

SILVA, T. R. Mechanicalbehavior of coating mortars with regranulated expanded cork. Monografia. Técnico Lisboa, julho, 2014.

\section{Agradecimentos}

Os autores agradecem à Universidade Federal de Santa Maria (UFSM) pelo apoio, infraestrutura e recursos para a realização da pesquisa e às empresas Supermix e Supertex pelo fornecimento dos materiais.

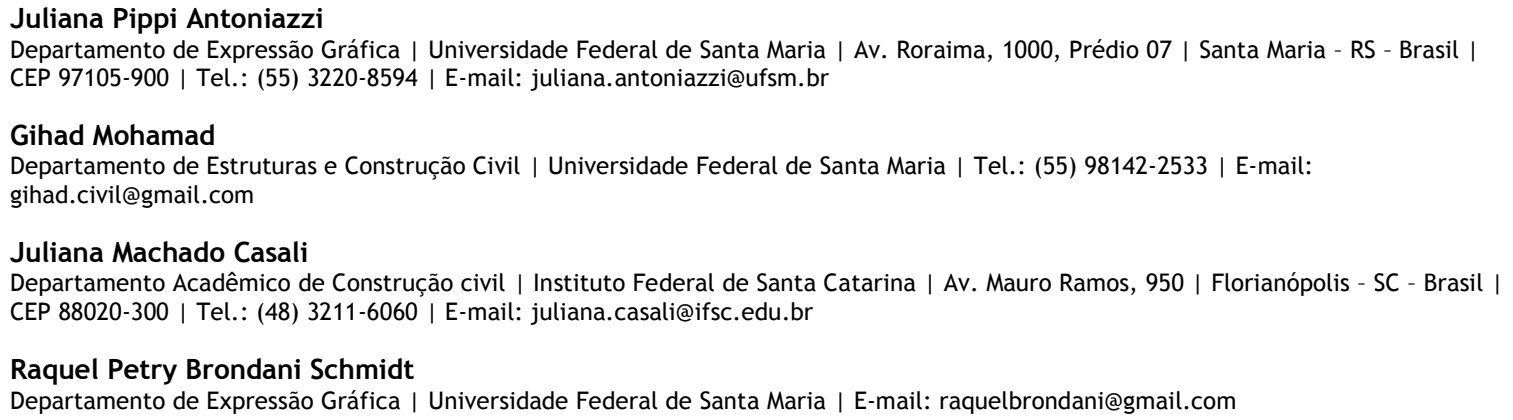

\section{Ambiente Construído}

Revista da Associação Nacional de Tecnologia do Ambiente Construído Av. Osvaldo Aranha, 99 - $3^{\circ}$ andar, Centro

Porto Alegre - RS - Brasil CEP $90035-190$

Telefone: +55 (51) 3308-4084

Fax: +55 (51) 3308-4054

www.seer.ufrgs.br/ambienteconstruido

E-mail: ambienteconstruido@ufrgs.br

This is an open-access article distributed under the terms of the Creative Commons Attribution License. 